\title{
A Forecast Advisory for Afternoon Thunderstorm Occurrence in the Taipei Basin during Summer Developed from Diagnostic Analysis*
}

\author{
Tsing-Chang Chen And JenQ-DaR Tsay \\ Department of Geological and Atmospheric Sciences, Iowa State University, Ames, Iowa \\ EUGENE S. TAKLE \\ Department of Geological and Atmospheric Sciences, and Department of Agronomy, Iowa State University, \\ Ames, Iowa
}

(Manuscript received 29 June 2015, in final form 22 December 2015)

\begin{abstract}
Summer is a dry season in northern Taiwan. By contrast, the Taipei basin, located in this region, has its maximum rainfall during summer (15 June-31 August), when $78 \%$ of this rainfall is contributed by afternoon thunderstorms. This thunderstorm activity occurs during only 20 days in summer. Because of the pronounced impacts on the wellbeing of three million people in the basin and the relative infrequency of occurrence, forecasting thunderstorm events is an important operational issue in the Taipei basin. The basin's small size $(30 \mathrm{~km} \times 60 \mathrm{~km})$, with two river exits and limited thunderstorm occurrence days, makes the development of a thunderstorm activity forecast model for this basin a great challenge. Synoptic analysis reveals a thunderstorm day may develop from morning synoptic conditions free of clouds/rain, with a NW-SE-oriented dipole located south of Taiwan and southwesterlies straddling the low and high of this dipole. The surface meteorological conditions along the two river valleys exhibit distinct diurnal variations of pressure, temperature, dewpoint depression, relative humidity, and land-sea breezes. The primary features of the synoptic conditions and timings of the diurnal cycles for the four surface variables are utilized to develop a two-step hybrid forecast advisory for thunderstorm occurrence. Step 1 validates the 24-h forecasts for the 0000 UTC (0800 LST) synoptic conditions and timings for diurnal variations for the first five surface variables on thunderstorm days. Step 2 validates the same synoptic and surface meteorological conditions (including sea-breeze onset time) observed on the thunderstorm day. The feasibility of the proposed forecast advisory is successfully demonstrated by these validations.
\end{abstract}

\section{Introduction}

Located in the southern part of East Asia, Taiwan's climate system annual variation undergoes two monsoon seasons: the southeast monsoon in summer and the northeast monsoon in winter. The summer monsoon rainfall appears in southern Taiwan, while the winter monsoon rainfall occurs in northern Taiwan (Chen et al. 2004). Because of this annual alternation of monsoon

\footnotetext{
* Supplemental information related to this paper is available at the Journals Online website: http://dx.doi.org/10.1175/WAF-D-150082.s1.

Corresponding author address: Tsing-Chang (Mike) Chen, Atmospheric Science Program, Dept. of Geological and Atmospheric Sciences, 3010 Agronomy Hall, Iowa State University, Ames, IA 50011.

E-mail: tmchen@iastate.edu
}

rainfall, summer is a dry season in northern Taiwan. In contrast to the seasonal monsoon rainfall variation in northern Taiwan, the major rainfall (close to $80 \%$ of total summer rainfall) in the Taipei basin (situated in northern Taiwan) is produced by afternoon thunderstorms (TSs) (Chen et al. 2014). The geographic size of this basin (Fig. 1) is about $30 \mathrm{~km}$ along the Tanshui River valley and $60 \mathrm{~km}$ along the Keelung River valley. Despite its small geographic size, the population in the Taipei basin is about three million people. The afternoon TS activity has a profound impact on the social well-being of this basin in several ways. The most important water supply to this basin is the TS rainfall. The downdrafts of cold air caused by TS rainfall over the mountain slopes south of the Taipei basin develop a cold front and create a wind surge ahead of this front. The surge may cause an air traffic hazard, while the local flooding generated by TS rainfall may result in traffic jams on land. The air ventilation in the Taipei basin is 


\section{(a) Network of observations (1993-2013)}

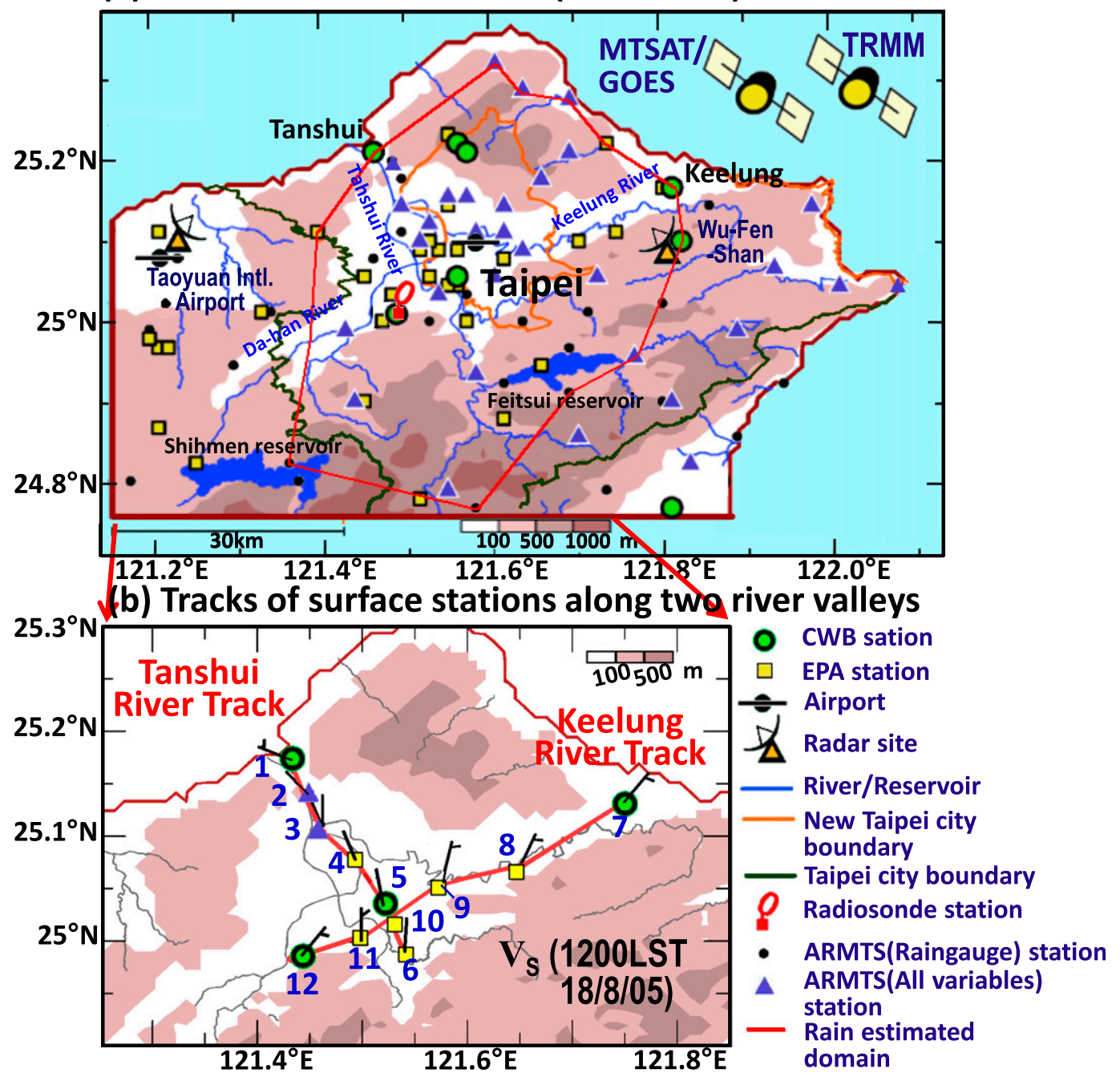

FIG. 1. Observational network in the Taipei basin. (a) Surface and radiosonde stations, radars, and satellites administrated by different agencies. The thick red line indicates the boundary of the rainfall occurrence domain linked to the sea breeze. (b) Two tracks of surface stations connected by red lines along the Tanshui (1-6) and Keelung (7-12) River valleys. Surface winds measured at 1200 LST 18 Aug 2005 are displayed as an example to illustrate the sea breezes along these two river valleys, labeled with red lines. The elevation scale of the orography is also added to each panel.

driven by the land-sea-breeze circulation pattern, which, in turn, regulates the diurnal variation of the basin meteorological conditions. The transition between the sea and land breezes on the no-thunderstorm (no TS) days follows sunset, but the afternoon TS rainfall enables this transition to occur immediately after TS rain has fallen.

To properly manage the water supply, to mitigate traffic hazards, and to reduce air pollution in the Taipei basin, day-ahead forecasts for the afternoon TS occurrence in this basin are crucial operations of the Taiwan's national weather service [namely, the Central Weather Bureau (CWB)] in summer. Because of the small geographic size of this basin, its TS forecast requires a spatially high-resolution numerical model. As pointed out by Yeh et al. (2012), the development of such a forecast model is beyond the current CWB's operational capability. The present study develops a practical forecast advisory for the afternoon TS activity in the Taipei basin to circumvent this predicament of operational forecasting. Recently, Lin et al. (2012) applied the fuzzy logic algorithm developed by Berenguer et al. (2006) to "quantitatively assess the TS occurrence probability" in the Taipei basin. Using radar and lightning data, Lin et al. (2011) classified the basin-scale meteorological conditions at the surface 
into TS and no-TS days for the large-scale environment without severe synoptic perturbation. The characteristic difference of the basin meteorological conditions for these two groups of summer days is indicated by four surface variables (vapor pressure, relative humidity, wind direction, and wind speed) at Tanshui, Taipei, and at Keelung in the late morning. The large-scale environmental conditions are monitored by use of four variables [convective available potential energy (CAPE), dewpoint depression $\Delta T_{d}$, and wind direction and speed at five levels in the lower half of the troposphere], as measured by radiosondes at Panchiao (WMO 46688). The 12 surface and 16 upper-air variables, as well as the presumed persistence of TS occurrence, were later used by Lin et al. (2012) as 29 predictors for the modified fuzzy logic algorithm to assess the TS occurrence probability. This statistical algorithm is operationally adopted by the CWB (Cheng and Lu 2013). The skill scores of TS occurrence made subjectively by the CWB forecaster reach $0.47-0.60$, but those made objectively using Lin et al.'s statistical approach showed somewhat of an improvement in the skill score (0.54-0.76).

When inputting the surface meteorological variables over four morning hours [0800-1200 local standard time (LST)] and the upper-air observation at 0800 LST (0000 UTC) into Lin et al.'s (2012) fuzzy logical algorithm, the following factors hamper their success rate in assessing the TS occurrence probability:

1) TS and no-TS days are identified without a clear distinction in the synoptic conditions between these two basin meteorological classifications.

2) Characteristic differences in the land-sea breeze over their life cycles between TS and no-TS days, particularly the impact of TS rainfall on the land-sea breeze's life cycle, are not considered.

3) The impact of the differences in the large-scale circulation over southwestern East Asia on the Taipei land-sea breezes between TS and no-TS days (i.e., the difference in large-scale forcing, affecting the land-sea-breeze circulation pattern between TS and no-TS days) is unclear.

4) Because of a lack of understanding involving the first three factors, the fuzzy logic algorithm adopted/ modified by Lin et al. (2012) to assess the TS occurrence probability does not offer a clear perspective of the large-scale forcing and the response of the basin's meteorological conditions to this forcing.

These concerns were clarified by a field experimentthe Taipei Basin Experiment (TBEX)—conducted in the Taipei basin and its surrounding areas for two summers (2004 and 2005). TS and no-TS days are defined using the synoptic conditions across Southeast/East Asia, the rainfall amount $\left(\geq 10 \mathrm{~mm} \mathrm{~h}^{-1}\right)$ in the basin, the onset time of the sea breeze, and the monsoon flow in the $500-850-\mathrm{hPa}$ layer. The analysis results of the experiment were reported upon by Chen et al. (2014, hereinafter C14) from two perspectives: 1) to distinguish the synoptic environment favorable for developing the afternoon TSs in the basin from that for no-TS (with a sea breeze) days and 2) to explore how the basin's diurnal variations of surface meteorological conditions are changed by the synoptic environment modifications produced by the occurrence of afternoon TSs.

Because the first perspective was gained from upperair soundings at Taipei and initial analysis of The Observing System Research and Predictability Experiment (THORPEX) Interactive Grand Global Ensemble (TIGGE; Bougeault et al. 2010), these results can be utilized to validate the operational forecasts at Taipei. Using measurements of meteorological variables by surface stations within and surrounding the basin, the second perspective was pursued. Thus, a two-step hybrid forecast advisory is developed in this study:

Step $1-$ The 24 -h forecasts of TIGGE on day $-1^{1}$ will be utilized to generate the threshold conditions for the morning synoptic environment and implications of some diurnal variations of the basin's meteorological circulation for possible thunderstorm occurrence on day 0 .

Step 2-The real-time measurements of surface meteorological variables inside the Taipei basin in the early morning and the morning operational synoptic report on day 0 are used to monitor the diurnal variation of the basin's meteorological conditions for possible occurrences of an afternoon thunderstorm on this day. Following this monitoring process, the updated day -1 forecast for the day 0 afternoon TS occurrence can be issued.

This two-step hybrid forecast advisory offers a more feasible means of supplementing the operational forecasts for thunderstorm activity within the Taipei basin.

The proposed forecast advisory of thunderstorm occurrence in the Taipei basin is developed from our understanding of the synoptic features and the diurnal variations of surface variables associated with TS and noTS days during the summer in the Taipei basin-obtained through the TBEX. This study is presented in the following manner. The identification of weather conditions/ systems and data used in this study are provided in section 2. Results obtained from the two perspectives are statistically summarized in section 3 , followed by section 4 with

\footnotetext{
${ }^{1}$ One day (24 h) prior to the occurrence of an event.
} 
synoptic and statistical analyses for the two perspectives with the 24 -h forecast on day -1 by TIGGE for all identified TS cases. Based upon results obtained from the two former sections, the forecast advisory for afternoon thunderstorm occurrence in the Taipei basin is outlined in section 5. The applicability/generality of this forecast advisory is also discussed. Validation of this proposed forecast advisory with the operational forecasts produced by these two global forecast systems for the synoptic environment of the East Asian monsoon circulation and local surface measurements are shown in section 6 . We conclude in section 7 with a summary of the study and suggestions for future improvements/developments of the proposed forecast advisory of thunderstorm occurrence in the Taipei basin.

\section{Identification of weather conditions/systems and data}

The present study is a sequel to the analysis of TBEX reported by $\mathrm{C} 14$, where a detailed description of data used for analysis can be found. To make this study more self-contained, the development and validation of the proposed hybrid forecast advisory for afternoon TS occurrence in the Taipei basin, a brief description of the identification of weather conditions/systems, the surface observations and upper-air soundings used to portray the diurnal variation of the land-sea breeze, and the operational assimilation data used to depict the synoptic condition of TS/no-TS days over Southeast/East Asia is presented in this section.

\section{a. Identification of weather conditions and systems}

\section{1) IDENTIFICATION OF LAND-SEA BREEZES WITH AND WITHOUT THUNDERSTORMS WITHIN THE BASIN}

Identification criteria for the land-sea breeze with and without afternoon thunderstorms are developed from the synoptic conditions over Southeast/East Asia and surface meteorological conditions in the Taipei basin by the land-sea breeze. The sea-breeze onset is determined by shortwave radiative heating on the mountains surrounding the basin, while the sea-breeze (SB)-land-breeze (LB) transition is determined by the longwave radiation cooling of the mountains. This noTS land-sea-breeze life cycle is shortened by afternoon TS rainfall. Identification criteria for TS and no-TS days are listed below:

(i) TS days with SB and afternoon thunderstorms The Taipei basin is cloud/rainfall free in the morning, but clouds appear in the afternoon.
Sea breezes, the inbound surface winds along the two river valleys (Fig. 1b), begin at about 1000 1030 LST, while land breezes, the outbound surface winds along these valleys, occur immediately after the TS rainfalls.

The maximum TS rainfall within the Taipei basin is $\geq 10 \mathrm{~mm} \mathrm{~h}^{-1}$.

Monsoon southwesterlies appear at 0000 UTC in the troposphere in the 500-850-hPa layer at Taipei. Any day with rainfall produced by a typhoon (TY), cold front (FT), or rainstorm (RS) is excluded, because the sea breeze cannot be driven/maintained by these external weather systems. Rain events produced by these systems are classified as being in the TS, no-SB group.

(ii) No-TS days with SB and clear sky

No cumulus convection/rainfall occurs in northern Taiwan from morning to midnight.

Sea breezes appear at 1000 LST at the rivers' exits, but at 1200 LST close to the mountain slopes south of the Taipei basin. The sea-land-breeze transition occurs after sunset.

TS activity is absent in the basin.

A well-organized east-west-oriented ridgeline from east China to the East China Sea develops north of Taiwan.

Easterlies/southeasterlies develop at 0000 UTC between 850 and $500 \mathrm{hPa}$ at Taipei.

Some North Pacific upper-level vortices pass across northern Taiwan.

(iii) No-TS, with SB and cloud/rain $\left(<10 \mathrm{~mm} \mathrm{~h}^{-1}\right)$ conditions throughout the day are observed.

(iv) No-TS, no-SB, clear sky conditions reported throughout the day without afternoon thunderstorms; this includes passage of some North Pacific upper-level vortices across northern Taiwan.

\section{2) EXTERNAL SYNOPTIC WEATHER SYSTEMS}

Four different severe synoptic weather systems across the Taipei basin were identified. They include TY, FT, RS, and a North Pacific upper-level vortex [related to the basin's weather conditions ii and iii of section $2 \mathrm{a}(1)]$. These weather systems can be identified from the surface analysis maps issued by the Japan Meteorological Agency (JMA), but criteria used to identify these four types of weather systems are given below:

(i) Rainstorms-Before the monsoon break, these storms bring heavy rainfall to southwestern Taiwan. The arrival of these storms may either follow the passage of fronts across northern Taiwan or without the presence of fronts. Fronts may bring rainfall to the Taipei basin, but summer rainfall for 
TABLE 1. Days of different weather conditions (last column) occurring within the Taipei basin for the period of 15 Jun-31 Aug during 2007-13. The * indicates a contribution from the North Pacific upper-level vortex.

\begin{tabular}{|c|c|c|c|}
\hline \multicolumn{2}{|c|}{ Group } & \multirow{2}{*}{$\begin{array}{l}\text { Weather system/conditions } \\
\text { TS, SB, afternoon/evening rainfall }\end{array}$} & \multirow{2}{*}{$\frac{\text { No. of days }}{20.1}$} \\
\hline $\mathrm{a}$ & a1 & & \\
\hline & (b1-b3) & TS, no SB, rain: external synoptic systems (RS, FT, TC) & $(14.4)$ \\
\hline & $\mathrm{a} 2(\mathrm{~b} 4 *)$ & No TS, SB, clear sky & $27.9\left(1.3^{*}\right)$ \\
\hline & a3 & No TS, SB, cloud/rain $\left(<10 \mathrm{~mm} \mathrm{~h}^{-1}\right)$ & 12.9 \\
\hline & $\mathrm{a} 4(\mathrm{~b} 4 *)$ & No TS, no SB, clear sky & $2.7\left(0.3^{*}\right)$ \\
\hline \multirow[t]{11}{*}{$\mathrm{b}$} & b1 & RS & 0.1 \\
\hline & b2 & Front location & \\
\hline & & $\leq 50 \mathrm{~km}$, rain at Taipei, no SB & 0.9 \\
\hline & & $>50 \mathrm{~km}$, rain at Taipei, SB & 0.4 \\
\hline & & $>50 \mathrm{~km}$, rain at Taipei, no SB & 0.2 \\
\hline & b3 & $\mathrm{TC}$ & \\
\hline & & $|\mathbf{V}| \geq 35 \mathrm{kt}$ with rain & 2.6 \\
\hline & & $|\mathbf{V}| \geq 35 \mathrm{kt}$ with no rain and no SB & 8.4 \\
\hline & & $|\mathbf{V}|<35 \mathrm{kt}$ with rain, TC center $>300 \mathrm{~km}$ from Taipei & 1.2 \\
\hline & & $|\mathbf{V}|<35 \mathrm{kt}$ with no rain and no SB, TC center $>300 \mathrm{~km}$ from Taipei & 0.6 \\
\hline & b4 & North Pacific upper-level vortex & 1.6 \\
\hline
\end{tabular}

this basin is not related to the rainstorm activity in southwest Taiwan.

(ii) Fronts-Located at a distance $\leq 50 \mathrm{~km}$ from Taipei, with rain at Taipei determined by the JMA surface analysis chart. Fronts may be located at a distance $>50 \mathrm{~km}$ from Taipei, but the rainband for these fronts is extended to cover the Taipei basin, as revealed by the TRMM PR distribution. This rainfall activity may or may not be coupled with SB.

(iii) Tropical cyclones-The Taipei basin is covered by $|\mathbf{V}| \geq 35 \mathrm{kt}$ (where $1 \mathrm{kt}=0.51 \mathrm{~m} \mathrm{~s}^{-1}$ ) during a tropical cyclone (TC) with rain or without rain and sea breeze. Some rainy days are caused by TCs, even with wind speed $|\mathbf{V}|<35 \mathrm{kt}$. Some no-SB days without rain are attributed to the TC flow, although $|\mathbf{V}|<35 \mathrm{kt}$. The TC centers of the last two categories are located at a distance $>300 \mathrm{~km}$ away from Taipei.

(iv) For the North Pacific upper-level vortex, during summer, the instability of the North Pacific midoceanic trough may lead to the genesis of the upper-level vortex, which possesses a descending dry/cold core encircled by the moist ascending air around the vortex (Chen et al. 2001). The North Pacific anticyclone often hinders the downward penetration of this vortex into the lower troposphere. Propagated westward by the trough westerlies, some of the upper-level vortices may move across Taiwan and suppress convection over the Taipei basin. The impact of these vortices may result in some no-TS, $\mathrm{SB}$, clear-sky or no-TS, no-SB, clear-sky days.

The East Asian summer monsoon undergoes two monsoon life cycles - the active and revival phasesseparated by a break (Chen et al. 2004). Spring rainstorms, afternoon thunderstorms, and fronts in southern Taiwan produce major rainfall during the active phase, while during the break-revival phase, rainfall is generated by afternoon thunderstorms and tropical cyclones over Taiwan. To determine how the TS activity affects the meteorological environment of the Taipei basin, the break-revival phase is determined by two factors: 1) the life cycle of the East Asian monsoon in terms of rainfall and 2) the averaged first day of thunderstorms occurring in the Taipei basin on 15 June, which is close to the monsoon break. Occurrence days for all possible weather conditions/systems in the Taipei basin during 15 June-31 August (78 days) over 2004-13 are presented in Table 1.

\section{b. Observational data in the Taipei basin}

The present study uses two different groups of data: observations and reanalysis results.

\section{1) OBSERVATIONS}

Observational data include the surface measurements made by a mesonet system and upper-air observation by radiosonde, radar, and satellite sources. During TBEX, a mesonet of surface observations was formed in the Taipei basin and its vicinity with surface stations operated by the CWB, and by the Environmental Protection Administration (EPA), Civil Aviation Administration (CAA), Automatic Rainfall and Telemetry System (ARMTS; Chen et al. 1999), and the Defense Weather Forecast Centers. These observations were supplemented by seven mobile automatic weather observation stations (AWOSs) and 58 schoolnet stations to enhance the station density within the TBEX network. 
After TBEX, the supplemental stations were removed. To monitor the diurnal variation of the basin's meteorological conditions, the already existing EPA stations substituted seven AWOS stations along the Tanshui River valley and the Keelung River valley. The revised Taipei basin mesonet is shown in Fig. 1a. The quality of the revised mesonet was carefully checked/validated against TBEX. The basic meteorological variables observed by this network are pressure $p_{s}$, temperature $T_{s}$, dewpoint $T_{d}$, relative humidity $\mathrm{RH}_{s}$, wind $\mathbf{V}_{s}$, and rainfall $P$, at the surface. Two tracks of surface stations along the Tanshui and Keelung River valleys (Fig. 1b) were utilized, as with TBEX, to monitor diurnal variations of the meteorological conditions within the basin. Upperair observations include WMO upper-air soundings, particularly $T_{d}$ and $\mathbf{V}$, at Panchiao (WMO 46688); radar observations at two sites [Taiwan Taoyuan International Airport and Wu-Fan Shan (WMO 46685)]; and satellite observations [Multifunctional Transport Satellites (MTSAT)/GOES-9] (Clark 1983; Faller 2005) for the Japanese IR images and the TRMM PR rainfall (Huffman and Bolvin 2012).

\section{2) OPERATIONAL WEATHER MAPS AND GLOBAL} ANALYZED DATA

Operational JMA daily surface analysis maps are supplemented with streamline charts superimposed by either IR results from MTSAT/GOES-9 or TRMM PR. These streamline charts are prepared with the TIGGE initial conditions and forecasts at synoptic times. The TIGGE initial analysis has a resolution of $0.25^{\circ} \times 0.25^{\circ}$ (2007-present).

The observational data in the Taipei basin, including surface and upper-air observations; the operational weather maps; and the globally assimilated data are used to generate 1) synoptic and meteorological statistics of the land-sea breeze for TS and no-TS days and 2) day 0 synoptic and surface meteorological conditions for step 2 of the proposed forecast advisory. The globally assimilated data and day -1 forecasts are used to prepare 1) synoptic and meteorological statistics of forecasts for all identified TS days and 2) day -1 surface and upper-air forecasts for step 1 of the proposed forecast advisory.

\section{Synoptic and meteorological statistics of the land-sea breeze for all TS and no-TS days}

Without the afternoon TS activity, the land-sea breeze is still active on the no-TS clear-sky days during the daytime. Thus, the synoptic conditions and the diurnal variation of the surface meteorological conditions for the latter group are adopted as benchmark characteristics of the basin's land-sea-breeze circulation. These characteristics can be utilized to quantitatively measure changes caused by afternoon TS activity. Characteristic changes of the basin's land-sea breeze can be applied to develop the forecast advisory for the TS occurrence in the Taipei basin. The 2-yr statistical analysis performed by $\mathrm{C} 14$ is replaced by the 7-yr period of 2007-13, so the latest initial analysis and forecasts generated by the TIGGE can be included in the statistical analysis of the current study. To avoid redundancy, the salient features that emerged from the characteristic differences of the land-sea breeze in the Taipei basin between the TS and no-TS days will be highlighted with the composite time series for $p_{s}, T_{s}$, $\Delta T_{d}, \mathrm{RH}_{s}$, and $\mathbf{V}_{s}$. A statistical analysis for changes to the synoptic conditions in Southeast/East Asia and the basic characteristics of the land-sea breeze in the Taipei basin are performed during the summer TS season after the onset date (15 June; determined in the online supplement to this paper). The salient features for these changes are highlighted in this section.

\section{a. Morning (0000 UTC) synoptic condition}

\section{1) Morning SynOptics OF Southeast/EAst ASIA}

The JMA surface analyses for 2007-13 are archived by the Japan Meteorological Business Support Center (http://www.jmbsc.or.jp/), and the 850-hPa streamline charts for TS and no-TS days over the same period are documented online as well (Chen et al. 2015). The major features of these synoptic charts at 0000 UTC are highlighted here. On the no-TS days, a well-developed surface high pressure ridge north of Taiwan extends westward from the western Pacific subtropical anticyclone to the East China Sea and east China. This ridge exerts two important impacts on the weather in northern Taiwan: 1) preventing/suppressing the convective development over northern Taiwan and 2) channeling the southeasterly flow of the subtropical anticyclone across Taiwan. This southeasterly flow is juxtaposed to the west with a surface low over the South China Sea and to the east with the well-developed subtropical Pacific anticyclone. On the TS days, this well-developed E-W-oriented surface ridge on the no-TS days yields to a weak NW-SE ridge around the northeast section of Taiwan. This synoptic structure allows the southwest monsoon flow to straddle a surface low over northern Indochina and an anticyclone over the Philippine Sea, and transports the warm moist air from the northern South China Sea to Taiwan to facilitate afternoon convection. These synoptic features for no-TS and TS days are summarized in the top half of the first row in Figure 2. 


\begin{tabular}{|c|c|c|c|c|c|c|c|c|c|}
\hline \multicolumn{6}{|c|}{$\begin{array}{c}\text { sunrise } \\
\text { (0504-0534 LST) }\end{array}$} & \multicolumn{2}{|c|}{$\begin{array}{l}\text { mean onset of TS rainfall } \\
1459 \text { LST at Taipei }\end{array}$} & \multicolumn{2}{|c|}{$\begin{array}{c}\text { sunset } \\
814-1845 \text { LST) }\end{array}$} \\
\hline $\begin{array}{l}\text { Local stan- } \\
\text { dard time }\end{array}$ & 5 & 6 & 8 & 10 & 12 & 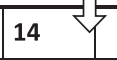 & 16 & 18 & 20 \\
\hline $\begin{array}{l}\text { Morning } \\
\text { radiosonde } \\
\text { observation } \\
\text { (Fig. 3) }\end{array}$ & \multicolumn{9}{|c|}{ 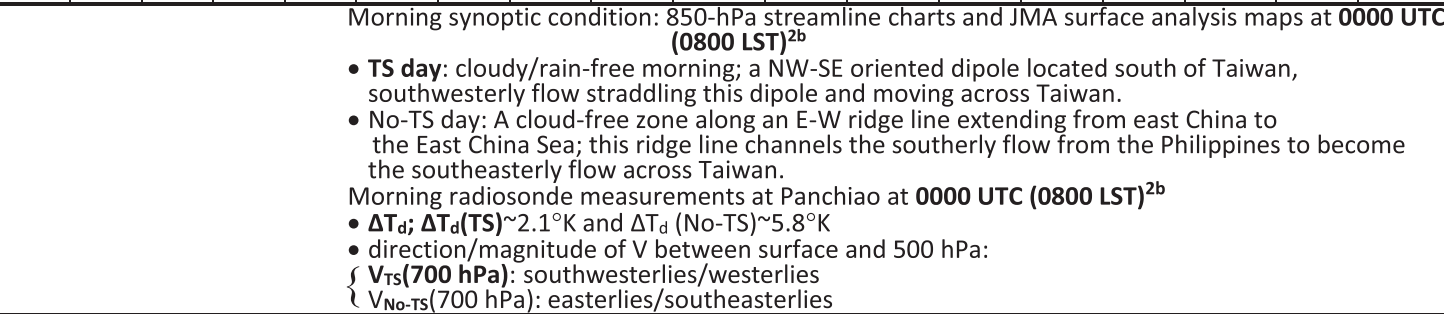 } \\
\hline $\begin{array}{l}p_{\mathrm{s}} \\
\text { (Fig. 4a) }\end{array}$ & \multicolumn{9}{|c|}{ 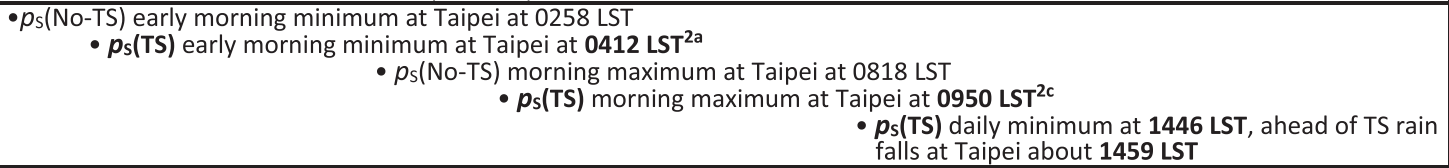 } \\
\hline $\begin{array}{l}T_{s} \\
\text { (Fig. 4b) }\end{array}$ & \multicolumn{9}{|c|}{ 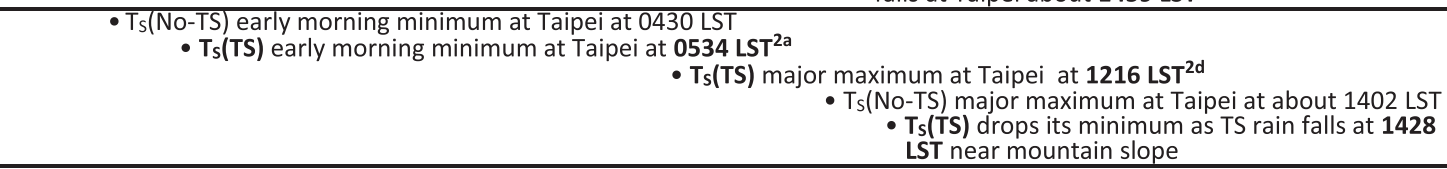 } \\
\hline$\Delta \mathbf{T}_{\mathrm{d}}$ (Fig. 4c) & \multicolumn{9}{|c|}{$\begin{array}{l}-\Delta \mathrm{T}_{\mathrm{d}}(\mathrm{TS}) \text { early morning drop at Taipei at } 0515 \mathrm{LST}^{2 \mathrm{a}} \\
\cdot \Delta \mathrm{T}_{\mathrm{d}}(\mathrm{TS}) \text { maximum at Taipei at } 1158 \mathrm{LST}^{2 \mathrm{~d}} \\
\cdot \Delta \mathrm{T}_{\mathrm{d}}(\mathrm{TS}) \text { sudden drop at } 1400-1600 \text { LST before TS rain falls }\end{array}$} \\
\hline $\mathrm{RH}_{\mathbf{s}}$ (Fig. 4d) & \multicolumn{9}{|c|}{$\begin{array}{l}\text { - } \mathrm{RH}_{\mathrm{s}}(\mathrm{TS}) \text { early morning overshooting at Taipei at } 0515 \mathrm{LST}^{2 \mathrm{a}} \\
\cdot \mathrm{RH}(\mathrm{TS}) \\
\text { minimum at Taipei at } 1158 \mathrm{LST}^{2 \mathrm{~d}} \\
\cdot \mathrm{RH}_{\mathrm{s}}(\mathrm{TS}) \text { sudden jump at } 1400-1600 \text { LST before TS rain falls }\end{array}$} \\
\hline $\begin{array}{c}\mathbf{V}_{\mathbf{s}} \text { (Figs. } 4 \mathrm{e} \\
\text { and f) }\end{array}$ & \multicolumn{9}{|c|}{$\begin{array}{r}-\mathrm{V}_{\mathrm{s}}(\mathrm{TS}) \text { and } \mathrm{V}_{\mathrm{S}} \text { (No-TS) SB onset at river exit station about } 0952 \mathrm{LST} \\
\cdot \mathrm{V}_{\mathrm{S}} \text { (TS) SB onset near mountain slope at } 1022 \text { LST }^{2 \mathrm{c}} \\
\cdot \mathrm{V}_{\mathrm{S}} \text { (No-TS) onset near mountain slopes at } 1203 \text { LST }\end{array}$} \\
\hline
\end{tabular}

FIG. 2. Occurrence of events revealed from synoptic conditions $\left(T, \Delta T_{d}, \mathbf{V}\right.$, and IR) observed by radiosonde and surface measurements for $p_{s}, T_{s}, \Delta T_{d}, \mathrm{RH}_{s}$, and $\mathbf{V}_{s}$ over a day within the Taipei basin. Superscripts $2 \mathrm{a}-2 \mathrm{~d}$ are used to indicate ingredients applied to form the twostep forecast advisory for the afternoon thunderstorm activity in the Taipei basin. The composite sounding $\left[T_{s}, T_{d}\right.$, and $\left.\mathbf{V}(700 \mathrm{hPa})\right]$ and timings of the $p_{s}, T_{s}, \Delta T_{d}, \mathrm{RH}_{s}$, and $\mathbf{V}_{s}$ salient features in their diurnal variations at Taipei for TS and no-TS days are shown in online supplement to this article.

\section{2) MORNing SOUNDING MEASUREMENTS AT TAIPEI}

Inferred from the synoptic contrast between TS and no-TS days, the synoptic system of the TS days is developed to transport warm, moist air from the northern South China Sea to Taiwan by the monsoon southwesterlies. The statistics of the 0000 UTC upper-air soundings at Panchiao (WMO 46688; station 12 in Fig. 1b) are highlighted below:

\section{- $\Delta T_{d}$ (dewpoint depression)}

The contrast between $\Delta T_{d}$ (TS) (Fig. 3a) and $\Delta T_{d}$ (no TS) (Fig. 3b) measured by the upper-air soundings at Panchiao for 141 TS and 195 No-TS days is presented in Figs. 3a and 3b, respectively, at the lowest level $(\sim 73 \mathrm{~m}$ above the ground) and at $500 \mathrm{hPa}$. Averaged $\Delta T_{d}$ measured at these two levels for both TS and no-TS days are summarized as $\Delta T_{d}$ (TS) $\sim 2.1 \mathrm{~K}$ and $\Delta T_{d}$ (no TS) $\sim 5.8 \mathrm{~K}$ at the surface, and $\Delta T_{d}$ (TS) $\sim 8.3 \mathrm{~K}$ and $\Delta T_{d}$ (no TS) $\sim 12.2 \mathrm{~K}$ at $500 \mathrm{hPa}$. Note that the variation of $\mathrm{RH}$ is inversely proportional to $\Delta T_{d}$ (Lawrence 2005). Apparently, the entire troposphere is moister during TS days than no-TS days.

\section{- $\mathbf{V}(700 \mathrm{hPa})$}

The $u(700 \mathrm{hPa})$ versus $v(700 \mathrm{hPa})$ scatter diagrams for 141 TS days (Fig. $3 c$ ) show $\mathbf{V}_{\text {TS }}(700 \mathrm{hPa})$ winds are always located within the southerly, westerly quadrant, but the majority of $\mathbf{V}_{\mathrm{No} \text {-TS }}(700 \mathrm{hPa})$ winds for 195 no-TS days (Fig. 3d) are located in the southerly, easterly quadrant. The averaged $\left|\mathbf{V}_{\text {TS }}(700 \mathrm{hPa})\right|$ is about $6.0 \mathrm{~m} \mathrm{~s}^{-1}$ southwesterly, while the averaged $\left|\mathbf{V}_{\mathrm{No}-\mathrm{TS}}(700 \mathrm{hPa})\right|$ is $4.2 \mathrm{~m} \mathrm{~s}^{-1}$ southeasterly.

Inferred from the contrast of the basic characteristics for $\Delta T_{d}$ and $\mathbf{V}(700 \mathrm{hPa})$ between TS and no-TS days, the warm, moist air mass is transported during the TS days by the monsoon southwesterly flow across the Taipei basin to develop an environment conducive to triggering the afternoon convection and TS activity.

\section{b. Basin meteorological conditions of $p_{s}, T_{s}, \Delta T_{d}$, $\mathrm{RH}_{s}$, and $\mathbf{V}_{s}$}

The meteorological conditions in the Taipei basin regulated by the land-sea breeze were depicted with five surface meteorological variables: $p_{s}, T_{s}, \Delta T_{d}, \mathrm{RH}_{s}$, and $\mathbf{V}_{s}$. Our attention focuses on the basic characteristic 


\section{Panchiao(WMO\#46688) 2007-2013}

\section{(a)TS}

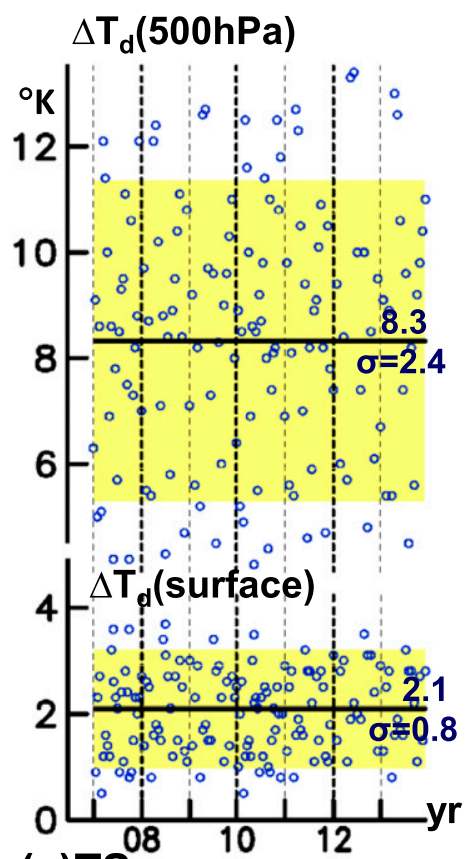

(c) TS

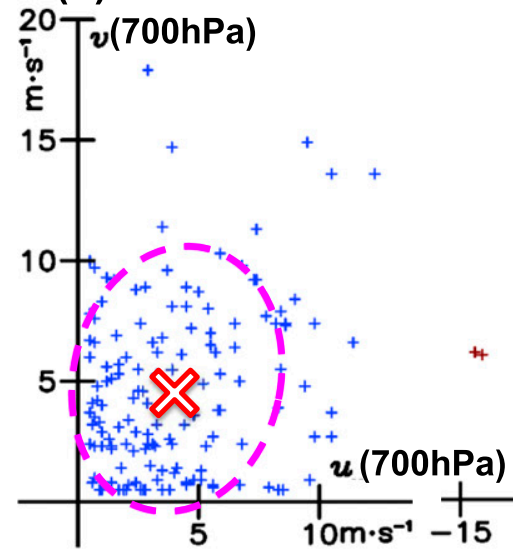

(b) No-TS

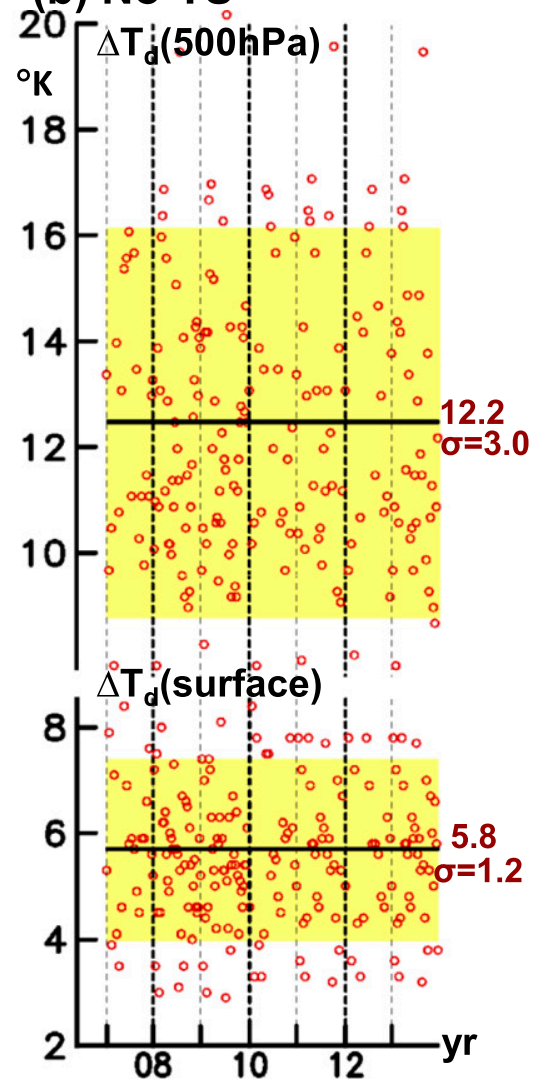

(d) No-TS

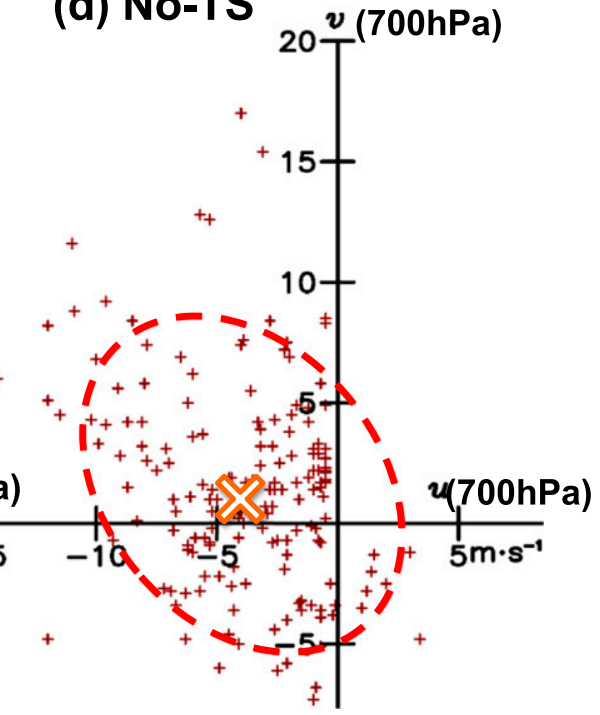

FIG. 3. Dewpoint depressions $\Delta T_{d}$ at $500 \mathrm{hPa}$ and the surface $(\sim 73 \mathrm{~m}$, the lowest level of soundings) measured by the upper-air soundings at Panchiao station (WMO 46688) at 0000 UTC for (a) TS days and (b) no-TS days. The yellow strip represents one standard deviation from the mean value marked by a thick black line. The scatter diagram for $(u, v)(700 \mathrm{hPa})$ is measured by the Panchiao soundings at 0000 UTC for (c) TS days and (d) no-TS days. The mean value of $|\mathbf{V}(700 \mathrm{hPa})|$ is marked by an open cross, while the 1.2 standard deviation with respect to the $|\mathbf{V}(700 \mathrm{hPa})|$ mean value is indicated by a dashed oblong. The purple (red) oblong belongs to TS (no-TS) days. Dashed open ellipses represent one standard deviation computed with the method introduced by Lefever (1926) to generate a "standard deviational ellipse" (Bui et al. 2012; http://cran.r-project.org/web/packages/aspace/index.html). The free statistical software used to generate the standard deviational ellipse can be acquired online (http://www.r-project.org/). 
differences of the land-sea-breeze cycle between TS and no-TS days. The composite diurnal cycles for $p_{s}, T_{s}, \Delta T_{d}$, and $\mathrm{RH}_{s}$ at Taipei (WMO 46692, station 5) and $\mathbf{V}_{s}$ at Tanshui (exit station 1), as well as at Jin-mei (mountain slope station, station 6), are shown in Fig. 4. Salient features for every variable emerging from these figures are highlighted below:

1) $p_{s}$ time series (Fig. 4a)

Four major features (maximum and minimum) in the $p_{s}$ (TS) variation are about $1-1.5 \mathrm{~h}$ behind those in the $p_{s}$ (no TS) variation, except the major daytime minimum is about $1.5 \mathrm{~h}$ ahead of the $p_{s}$ (no TS) major daytime minimum, caused by the occurrence of an afternoon thunderstorm and its rainfall. Both $p_{s}$ (TS) and $p_{s}$ (no TS) time variations over a day exhibit a distinctive semidiurnal variation. Shown by Lindzen (1968) and Lindzen and Chapman (1969), the semidiurnal tide is generated through the $\mathrm{O}_{3}$ interaction with the shortwave solar variation in the upper stratosphere. Thus, the minimum-maximum transition of $p_{s}$ seems to be linked with sunrise and sunset. The semidiurnal components for both $p_{s}$ (TS) and $p_{s}$ (no TS) should be coincident in time. Compared to $p_{s}$ (no TS), the delay of the $p_{s}$ (TS) early morning maximum, daytime maximum, and late night maximum, and the advance of the daytime major minimum are attributed to the diurnal component of $p_{s}$ (TS). A sudden jump in $p_{s}$ in the afternoon is caused by the mesohigh formation by the thunderstorm downdraft.

2) $T_{s}$ time series (Fig. 4b)

Longwave radiation cools the surface during clear dry nights more than during moist cloudy nights (e.g., Hess 1979; Liou 2002). Thus, the early morning $T_{s}$ (no TS) minimum occurs about $1 \mathrm{~h}$ earlier than the early $T_{s}$ (TS) minimum at about 0534 LST. After sunrise, the shortwave radiative heating and warm, moist air advection by the monsoon southwesterly flow warm $T_{s}$ (TS) to reach its maximum at $1216 \mathrm{LST}$. In contrast, without the warm moist southwesterly flow, $T_{s}$ (no TS) reaches its maximum at $1401 \mathrm{LST}$, about $2 \mathrm{~h}$ behind the occurrence of the $T_{s}$ (TS) maximum. This time lag for the $T_{s}$ (no TS) noontime maximum is attributed to the fact that $T_{s}$ (TS) drops quickly to reach its minimum, as soon as the TS rain falls at 1522 LST.

3) $\Delta T_{d}$ and $\mathrm{RH}_{s}$ time series at Taipei (Figs. $4 \mathrm{c}, \mathrm{d}$ )

The diurnal variations of $\Delta T_{d}$ (Fig. $4 \mathrm{c}$ ) and $\mathrm{RH}_{s}$ (Fig. 4d) are opposite. To save space, we shall focus only on the contrast between variations of $\mathrm{RH}_{s}$ and $T_{s}$. The variation of $\mathrm{RH}_{s}$ is almost opposite to that of $T_{s}$. This inverse relationship holds relatively well

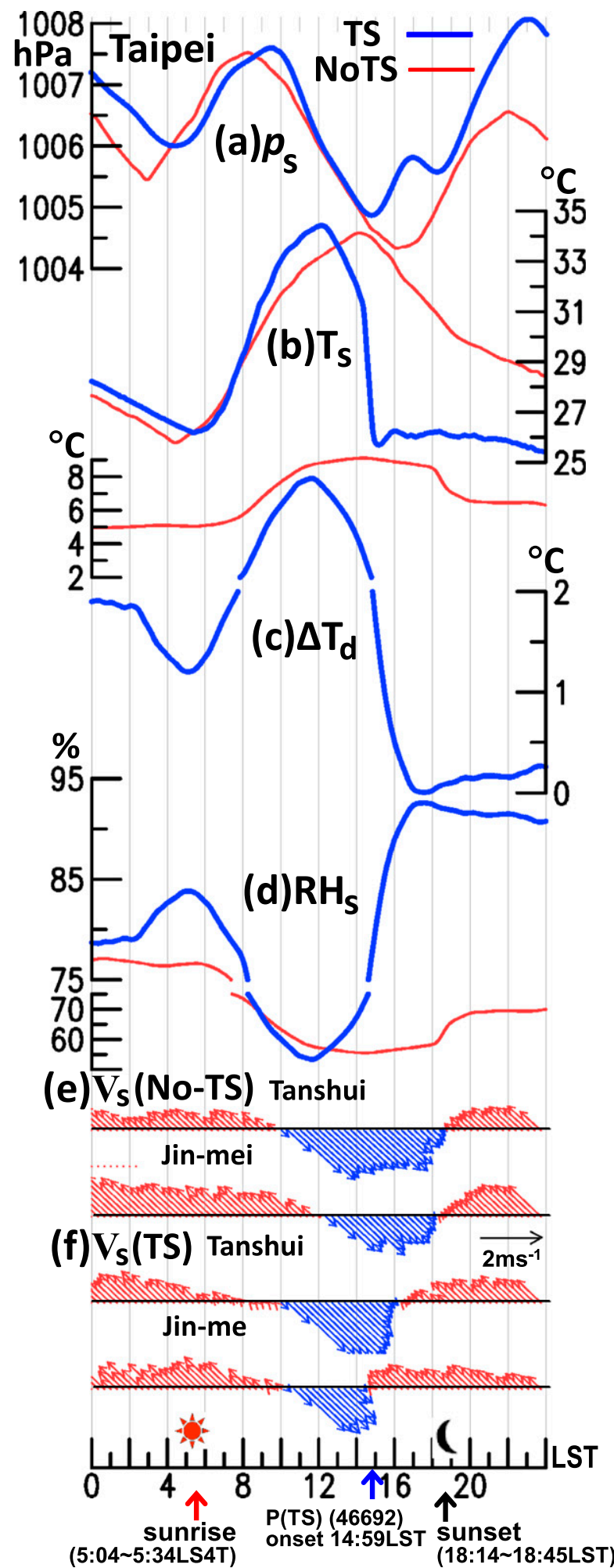

FIG. 4. Composite time series of (a) $p_{s}$, (b) $T_{s}$, (c) $\Delta T_{d}$, and (d) $\mathrm{RH}_{s}$ at the Taipei station (WMO 46692) for TS (blue solid line) and no-TS (red solid line) days. Composites of (e) no-TS and (f) TS $\mathbf{V}_{s}$ at the exit station on the Tanshui River (WMO 46690) and the mountain slope station of Jin-me (EP002). The red (blue) wind vector is for the land (sea) breeze. 
between $\mathrm{RH}_{s}$ (TS) and $T_{s}$ (TS). At sunrise, $\mathrm{RH}_{s}$ (TS) $\left[\Delta T_{d}\right.$ (TS)] exhibits a moderate overshooting (drop) $(\sim 5 \%)\left(\sim 1.2^{\circ} \mathrm{C}\right)$, when $T_{s}$ (TS) drops to its early morning minimum. For some limited no-TS days ( $14 \%), \mathrm{RH}_{s}$ (no TS) shows an overshooting. However, a majority of the $\mathrm{RH}_{s}$ (no TS) cases do not respond to the $T_{s}$ (no TS) early morning minimum with an overshooting. When $T_{s}$ (TS) reaches its maximum at about $1200 \mathrm{LST}, \mathrm{RH}_{s}$ (TS) also drops to its minimum close to noon. After noon, $\mathrm{RH}_{s}$ (TS) increases as soon as $T_{s}$ (TS) begins to drop from its noon maximum. When the afternoon TS rain falls, $T_{s}$ (TS) drops to its minimum and $\mathrm{RH}_{s}$ (TS) markedly increases to reach its evening maximum before sunset. In contrast, following the $T_{s}$ (no TS) increase after sunrise, the $\mathrm{RH}_{s}$ (no TS) gradually decreases until $T_{s}$ (no TS) reaches its minimum at about 1401 LST. We observe that $\mathrm{RH}_{s}$ (no TS) does not change significantly, even when $T_{s}$ (no TS) cools, but $\mathrm{RH}_{s}$ (no TS) shows a minor jump around sunset. The $\mathrm{RH}_{s}$ (no TS) response to the $T_{s}$ (no TS) variation does not seem as sensitive as $\mathrm{RH}_{s}$ (TS) to the $T_{s}$ (TS) variation.

4) $\mathbf{V}_{s}$ time series at Tanshui and Jin-me (Fig. 4d)

For the no-TS group, the SB onset begins at the rivers' exits around 1000 LST, but starts around 1200 LST near the mountain slopes. The SB cessation occurs immediately after sunset near the mountain slopes, about a half hour ahead of the river exit stations. For the TS group, the timings of SB onset and cessation are different from the no-TS group in several ways. The SB (TS) onset starts at 1000 LST at the rivers' exits, as the SB (no TS) onsets, but just slightly before 1030 LST near the mountain slopes. The SB (TS) cessation occurs near the mountain slopes, when TS rain falls at about 1430 LST, but at about 1630 LST at the rivers' exits. The no-TS SBLB transition near the mountain slopes occurs at the onset of sunset (close to 1800 LST), but this transition is about 1900 LST at the rivers' exits. Thus, the SB (no TS) life cycle is about $6 \mathrm{~h}$ near the mountain slopes and $9 \mathrm{~h}$ at the river exits. In contrast, the SB (TS) life cycle is shorter than that of SB (no TS), about $4.5 \mathrm{~h}$ near the mountain slopes and $6.5 \mathrm{~h}$ at the rivers' exits.

Summarized in Figure 2, the distinctive differences for the synoptic conditions in Southeast/East Asia and the meteorological conditions for the land-sea breezes in the Taipei basin between TS and no-TS days provide the excellent basic ingredients necessary to develop a forecast advisory for the potential occurrence of afternoon thunderstorms inside this basin.

\section{Synoptic and meteorological statistics of forecasts for all identified TS days}

Systematic differences in the synoptic system and large-scale circulation in Southeast/East Asia between TS and no-TS days were presented in section 3. If these systematic differences can be predicted to a certain degree a day ahead of the TS occurrence in the Taipei basin, these forecasts can be incorporated as part of the forecast advisory. The synoptic system and the largescale circulation pattern in this region, the synoptic conditions detected by the Panchiao soundings, and even some meteorological variables (e.g., $p_{s}, T_{s}, \Delta T_{d}$, and $\mathrm{RH}_{s}$ ) predicted by TIGGE for the next day in Taipei basin may carry the signal of afternoon thunderstorms in this basin. The 24-h forecasts of the day -1 synoptic system and large-scale circulation seen by TIGGE may also bear the basin's TS signal and be useful for confirming the TIGGE results.

\section{a. Forecast morning (0000 UTC) synoptic conditions}

\section{1) Forecast For Southeast/East Asian MORNING SYNOPTICS}

The 24-h forecasts of the day -1 synoptic system during TIGGE for all identified TS days during the 2007-13 period are validated against the day 0 observation synoptic system.

\section{(i) Day 0 Southeast/East Asian synoptic conditions: TS occurrence day}

There is a lack of the westward extension of the North Pacific subtropic anticyclone to block the aforementioned monsoon southwesterly flow. Thus, the surface synoptics during the TS day in Southeast/ East Asia are characterized by a NW-SE-oriented dipole, a north Indochina low center, and a Philippine Sea anticyclone to maintain the monsoon's southwesterly flow and transport warm moist air from the northern South China Sea to Taiwan. This synoptic condition is well forecasted by TIGGE $(\sim 100 \%$ of 141 days for the $2007-13$ period) in $24 \mathrm{~h}$.

\section{(ii) Composite TS circulation in Southeast/East Asia}

The low-level Asian continental thermal low is encircled by monsoon westerlies around south Asia and monsoon southwesterlies around Southeast/East Asia. This low-level monsoon flow is embedded in three pairs of troughs (thick, solid blue line) and ridges (thick, dashed red line) in the observed eight-summer-mean $\langle\mathbf{V}(700 \mathrm{hPa})\rangle$ streamline chart (Fig. 5a). The low-level Asian monsoon circulation depicted with the 24-h forecasts for day -1 by TIGGE $\langle\mathbf{V}(700 \mathrm{hPa})\rangle$ (Fig. 5b) also exhibit three pairs 


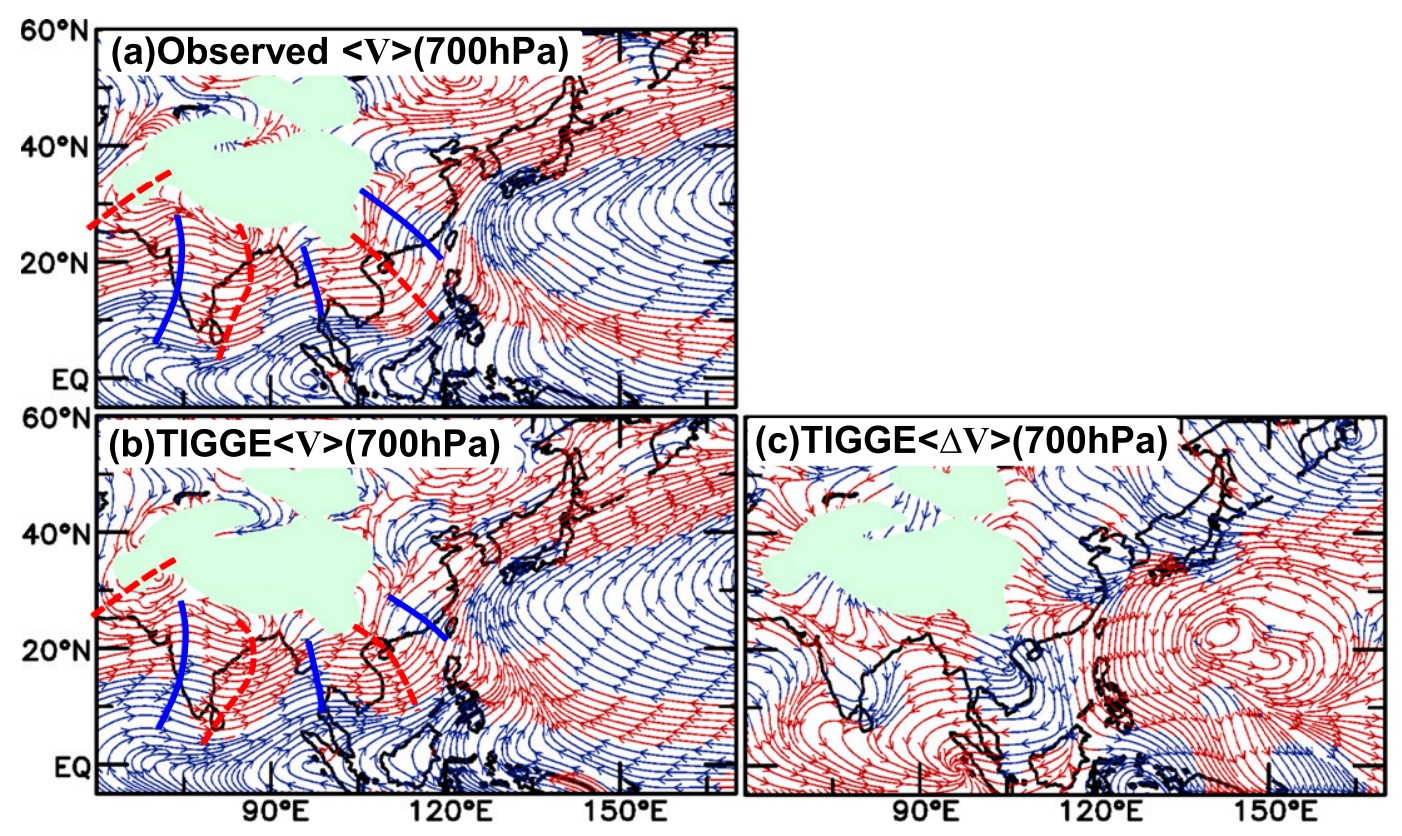

FIG. 5. (a) The summer-mean 700-hPa circulation at 0000 UTC for the 2007-13 period depicted with the TIGGE analysis. (b) The 24-h forecast of summer-mean 700-hPa circulation at 0000 UTC portrayed by TIGGE. The cyclonic and anticyclonic flows are depicted by red and blue streamlines, respectively. The trough and ridge lines for the summer-mean 700-hPa monsoon flow in south and Southeast Asia in (a) are indicated by thick solid blue and thick dashed red lines, respectively. (c) Differences between the 24-h forecast and initial TIGGE analysis. The cyclonic and anticyclonic 700-hPa departure flows are also portrayed by red and blue streamlines, respectively.

of monsoon troughs and ridges around the Asian continent. As indicated by the departure of TIGGE $\langle\mathbf{V}(700 \mathrm{hPa})\rangle$ (Fig. 5b) from observed $\langle\mathbf{V}(700 \mathrm{hPa})\rangle$ (Fig. 5a), that is, GFS(TIGGE) $\langle\Delta \mathbf{V}(700 \mathrm{hPa})\rangle$ in Fig. $5 c$, these troughs and ridges are underforecasted. The major underforecasted features are the monsoon troughs over Pakistan, the western Bay of Bengal, the South China Sea, and the three monsoon ridges. The departure of composite TS circulation from the seasonalmean circulation, observed $\Delta \mathbf{V}_{\mathrm{TS}}(700 \mathrm{hPa})$, exhibits a well-organized anticyclonic shear flow along the Asian coasts (Fig. 6a), as does the departure of composite TS circulation for the 24-h forecasts from the seasonal-mean flow, TIGGE $\Delta \mathbf{V}_{\text {TS }}(700 \mathrm{hPa})$ (Fig. 6b). But, as shown by $\delta \mathbf{V}_{\text {TS }}(700 \mathrm{hPa})\left[=\right.$ TIGGE $\Delta \mathbf{V}_{\mathrm{TS}}(700 \mathrm{hPa})-$ observed $\Delta \mathbf{V}_{\mathrm{TS}}(700 \mathrm{hPa}$ )] (Fig. 6c), the departure of composite TS anticyclonic shear flow is underforecasted, as is the southwesterly monsoon flow toward Taiwan.

2) Morning (0000 UTC) VerTiCAL PROFILES OF FORECASTS VERSUS SOUNDINGS AT TAIPEI

\section{(i) $\Delta T_{d}$}

The contrast between the averaged observed (Fig. 3a) and TIGGE-forecasted (Fig. 7a) $\Delta T_{d}$ for all TS days is made. The observed $\Delta T_{d}$ (surface) $\simeq 2.1 \mathrm{~K}$ and $\Delta T_{d}$ $(500 \mathrm{hPa}) \simeq 8.3 \mathrm{~K}$, while the TIGGE $\Delta T_{d}($ surface $) \simeq 2.8 \mathrm{~K}$ and $\Delta T_{d}(500 \mathrm{hPa}) \simeq 9.7 \mathrm{~K}$. Apparently, the latter groups are drier than the former group, but they are not as dry as the observed no-TS cases shown in Fig. 3b. Regardless of this assessment, $\mathrm{RH}$ (shown in section $4 \mathrm{~b}$ ) is somewhat underforecasted for all TS days.

\section{(ii) $\mathbf{V}(700 h P a)$}

Inferred from Fig. 6, the observed southwesterly monsoon flows for all identified TS days are well forecasted by TIGGE $24 \mathrm{~h}$ ahead of TS days, although they are underforecasted. To confirm this inference, the scatter diagrams of observed and forecasted results $[u(700 \mathrm{hPa})$ versus $v(700 \mathrm{hPa})]$ for all TS days are shown in Fig. 7. Both TIGGE (Fig. 7b) $[u(700 \mathrm{hPa})$ versus $v(700 \mathrm{hPa})]$ winds are clustered in the southerly, westerly quadrant. Apparently, the forecasted $\mathbf{V}(700 \mathrm{hPa})$ winds of TS days in the Taipei basin are all southwesterly. The averaged observed $\mathbf{V}(700 \mathrm{hPa})$ $\simeq 6.0 \mathrm{~m} \mathrm{~s}^{-1}$, but the averaged TIGGE $\mathbf{V}(700 \mathrm{hPa})$ winds are about $5.0 \mathrm{~m} \mathrm{~s}^{-1}$. Of course, the southwesterly flow for TS days across Taipei is somewhat underforecasted, compared to the observed results shown in Fig. 3c.

The southwesterly airflows for TS days are underforecasted in moisture and speed by TIGGE. However, these meteorological properties for monsoon southwesterlies are well forecasted to a certain degree. 


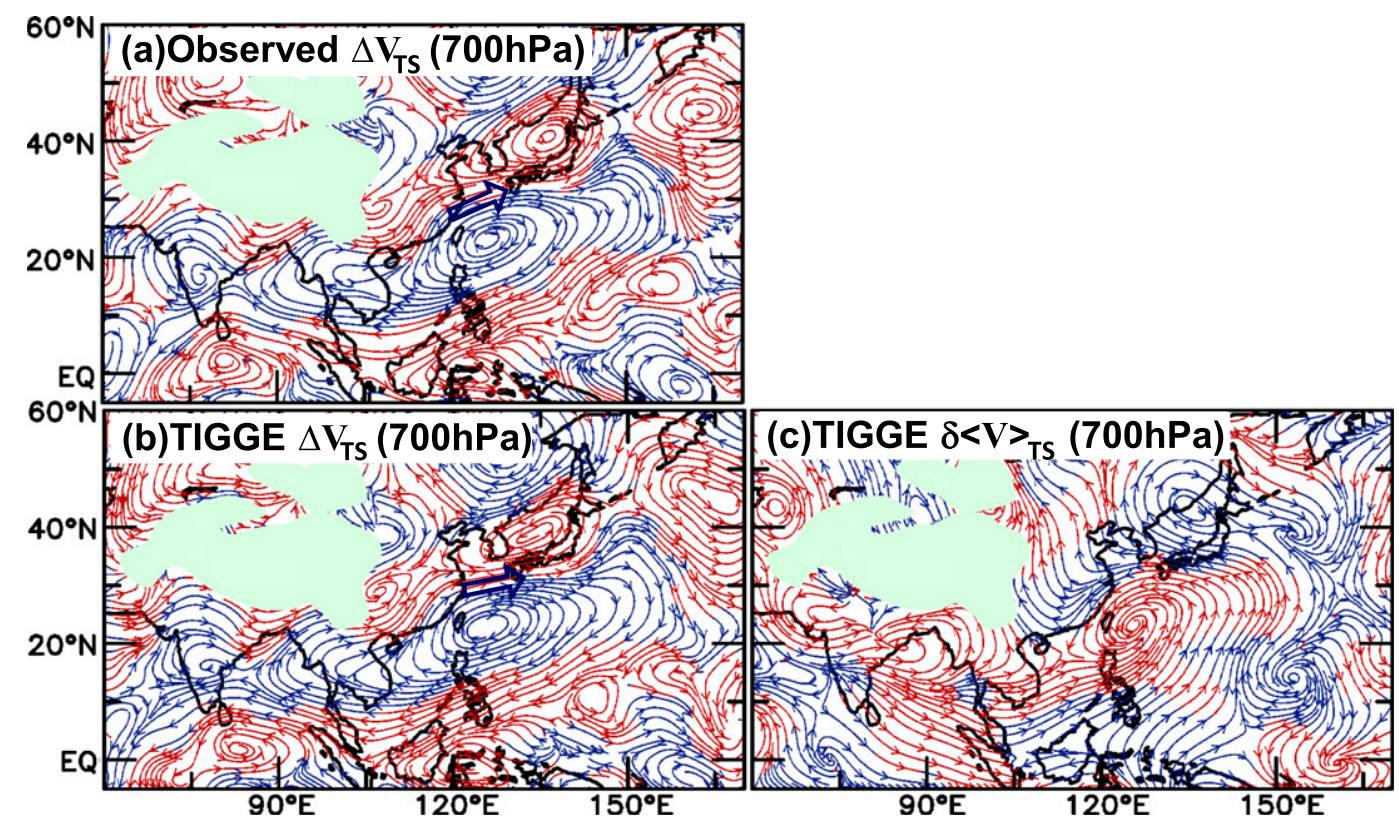

FIG. 6. The composite 700-hPa departure flows at 0000 UTC for the TS days during 15 June-31 August over the period of 2007-13 depicted by the (a) TIGGE initial analysis and (b) TIGGE 24-h forecast. (c) The difference between the 24-h forecast and initial analysis of TIGGE [where (b) - (a) $=$ TIGGE $\delta<\mathbf{V}>_{\mathrm{TS}}(700 \mathrm{hPa})$ ]. The cyclonic and anticyclonic departure flows at $700 \mathrm{hPa}$ are portrayed by red and blue streamlines, respectively. The statistical significance of composite $700-\mathrm{hPa}$ streamline charts is shown in the online supplement to this article (first figure).

\section{b. Forecast meteorological conditions at Taipei}

The statistical analysis of synoptic conditions with the 24-h forecasts of day -1 for all identified TS days demonstrates that TIGGE provides a certain level of forecastability of the TS signal in the Taipei basin. The surface wind vectors within the basin undergo significant spatial variation because of the complicated terrain and building distribution. Although the TIGGE $\mathbf{V}_{s}$ forecasts match well in the lowest-level $(\sim 73 \mathrm{~m})$ wind vectors measured by Panchiao soundings (section $4 \mathrm{a}$ ), we should focus only on the diurnal variations for $p_{s}, T_{s}, \Delta T_{d}$, and $\mathrm{RH}_{s}$, as forecasted by TIGGE $24 \mathrm{~h}$ ahead of the TS occurrence at Taipei. It will be shown in section 6 that most ( $>80 \%$ ) of the $p_{s}, T_{s}, \Delta T_{d}$, and $\mathrm{RH}_{s}$ early/late morning and noontime extreme signals (minima/maxima) in the Taipei basin appear in the day -1 24-h forecasts of TIGGE for 141 TS days. In contrast, only about $50 \%-55 \%$ of the $T_{s}, \Delta T_{d}$, and $\mathrm{RH}_{s}$ after noontime extreme signals at Taipei show up in the forecasts. This comparison between the observations and the TIGGE TS days leads us to prepare the composite 24-h composite time series of $p_{s}, T_{s}, \Delta T_{d}$, and $\mathrm{RH}_{s}$ for observation with $100 \%$, for TIGGE with $78 \%, 60 \%, 51 \%$, and $51 \%$, respectively, of 141 TS days. The composite 24 -h forecasts for the diurnal variations of $p_{s}, T_{s}, \Delta T_{d}$, and $\mathrm{RH}_{s}$ (red lines for TIGGE) against those observed (thick, dark blue line) are shown in Fig. 8:

1) The temporal resolution of the TIGGE forecasts is $3 \mathrm{~h}$. Despite the limits of the temporal-spatial resolutions, the diurnal variations of $p_{s}, T_{s}, \Delta T_{d}$, and $\mathrm{RH}_{s}$ for more than half of the 141 TS days are well depicted. In contrast, the $p_{s}$ jump $(\sim 1 \mathrm{hPa})$ and the $T_{s}$ drop during the passage for the TS mesohigh do not appear in the TIGGE forecasts.

2) The semidiurnal variation for $p_{s}$ and the diurnal variations for $T_{s}, \Delta T_{d}$, and $\mathrm{RH}_{s}$ for Taipei forecasted by TIGGE coincide well with the results observed, although the amplitudes for these forecasted variables are smaller.

3) The timings for the $p_{s}$ and $T_{s}$ early morning minima, $\mathrm{RH}_{s}\left(\Delta T_{d}\right)$ early morning moderate overshooting (drop), the late morning $p_{s}$ maximum, the noontime $T_{s}$ and $\Delta T_{d}$ maxima, and $\mathrm{RH}_{s}$ minima are well predicted by TIGGE.

To incorporate the TIGGE forecasts as part of the forecast advisory for afternoon TS occurrence in the Taipei basin, at least timings of morning salient features for the $p_{s}, T_{s}, \Delta T_{d}$, and $\mathrm{RH}_{s}$ diurnal variations should be properly forecasted by the TIGGE 24-h forecast ahead of the TS occurrence. This requirement is well met by the majority of the TIGGE forecasts (Fig. 9) in comparison with the observations.

\section{Forecast advisory scheme for afternoon thunderstorms in the Taipei basin}

Comparisons of the upper-air synoptic environment around Taiwan and the basin-scale surface 


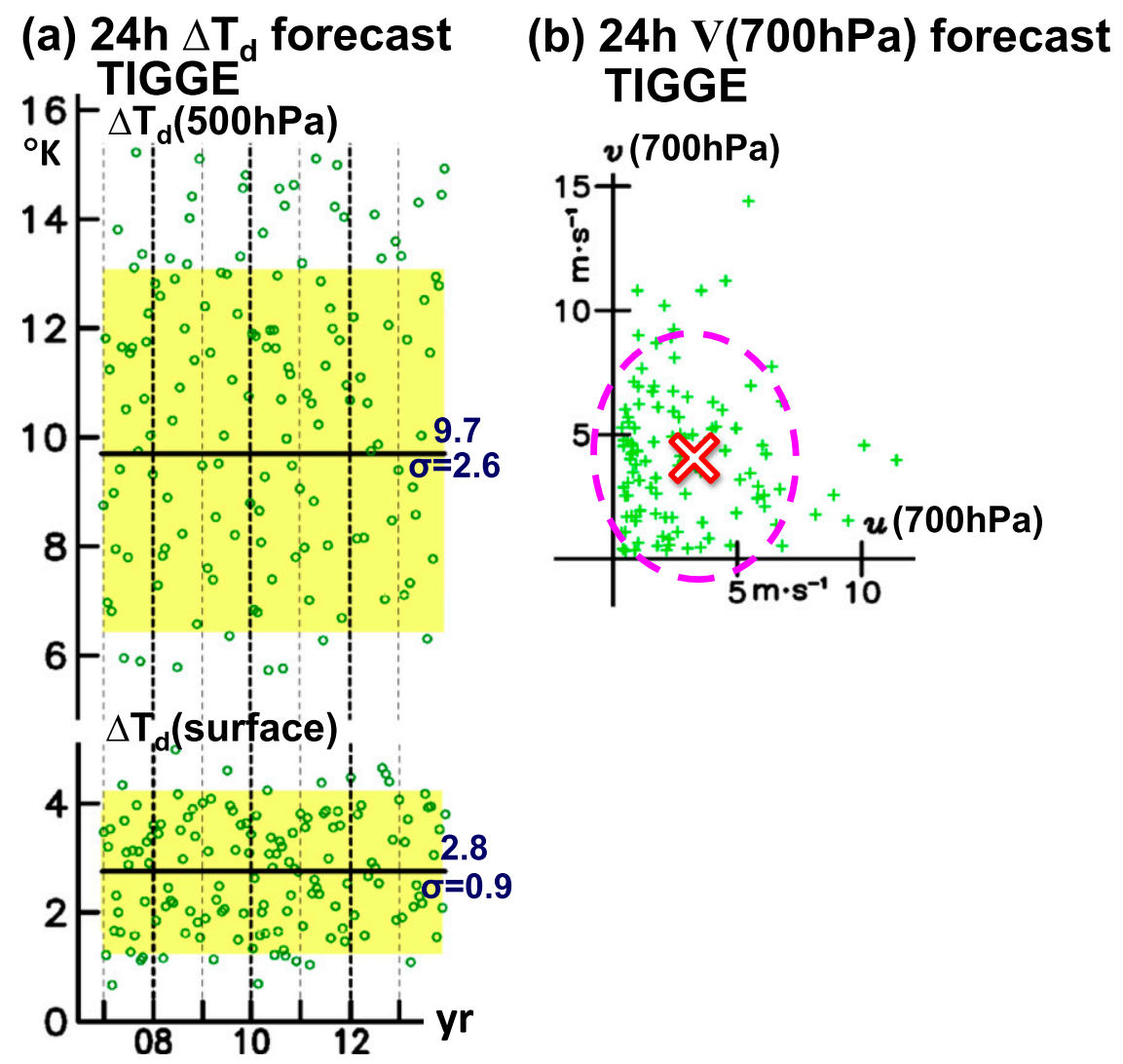

FIG. 7. As in Fig. 3, but for (a) TS day dewpoint depression $\Delta T_{d}$ at $500 \mathrm{hPa}$ and the surface at 0000 UTC and (b) TS day scatter diagram for $[u(700 \mathrm{hPa}), v(700 \mathrm{hPa})]$ at $0000 \mathrm{UTC}$ for the TIGGE 24-h forecast. Open red crosses depict mean values; the dashed open ellipse represents one standard deviation computed with the method introduced by Lefever (1926) to generate a standard deviational ellipse.

meteorological conditions in the Taipei basin between TS and no-TS days are made in sections 3 and 4 using day 0 observations and the day -1 ( $24 \mathrm{~h})$ TIGGE forecast, respectively, for afternoon TS occurrences on day 0. Based on statistical analyses for the upper-air synoptic conditions and the event timings of salient features in the diurnal variations of the surface meteorological conditions in the Taipei basin, a two-step hybrid forecast advisory for the afternoon TS occurrence is developed. The procedure for this forecast advisory is outlined by the flowchart of event timings shown in Fig. 10. The day $-1(24 \mathrm{~h})$ TIGGE forecast for the possible afternoon TS occurrence in the Taipei basin issued as part of step 1 is confirmed by the relay forecast made by step 2 .

\section{a. Step 1: Day -1 (24h prior to TS occurrence) forecast for the potential afternoon TS occurrence}

The day -1 TIGGE forecast at Taipei is used to predict the potential afternoon TS occurrence at Taipei on day 0 through the following four substeps:
- Step 1a (early morning) —Forecast is made for minima of $p_{s}, T_{s}$, and $\Delta T_{d}$, and a maximum (overshooting) of $\mathrm{RH}_{s}$. - Step 1b [morning 0000 UTC (0800 LST)]-The three required surface synoptic features are determined with surface synoptic maps/streamline charts with the day -1 TIGGE forecasts and the upper-air vertical profiles of $\Delta T_{d}$ and southwesterly flow in the lower troposphere at Taipei.

- Step 1c (late morning) - $p_{s}$ is maximum.

- Step 1d (noontime)-Maxima of surface $\Delta T_{d}$ and $T_{s}$ forecast, and $\mathrm{RH}_{s}$ minimum.

If the threshold values for criteria shown in the righthand column for the items listed in the middle column of Figure 11a can be met by the day -1 TIGGE forecasts, the potential afternoon TS occurrence the next day (day 0 ) is operationally issued.

\section{b. Step 2: Day 0 observations in the Taipei basin}

The step 1 procedure (with four substeps) for this forecast advisory is repeated by step 2 with the following changes: 


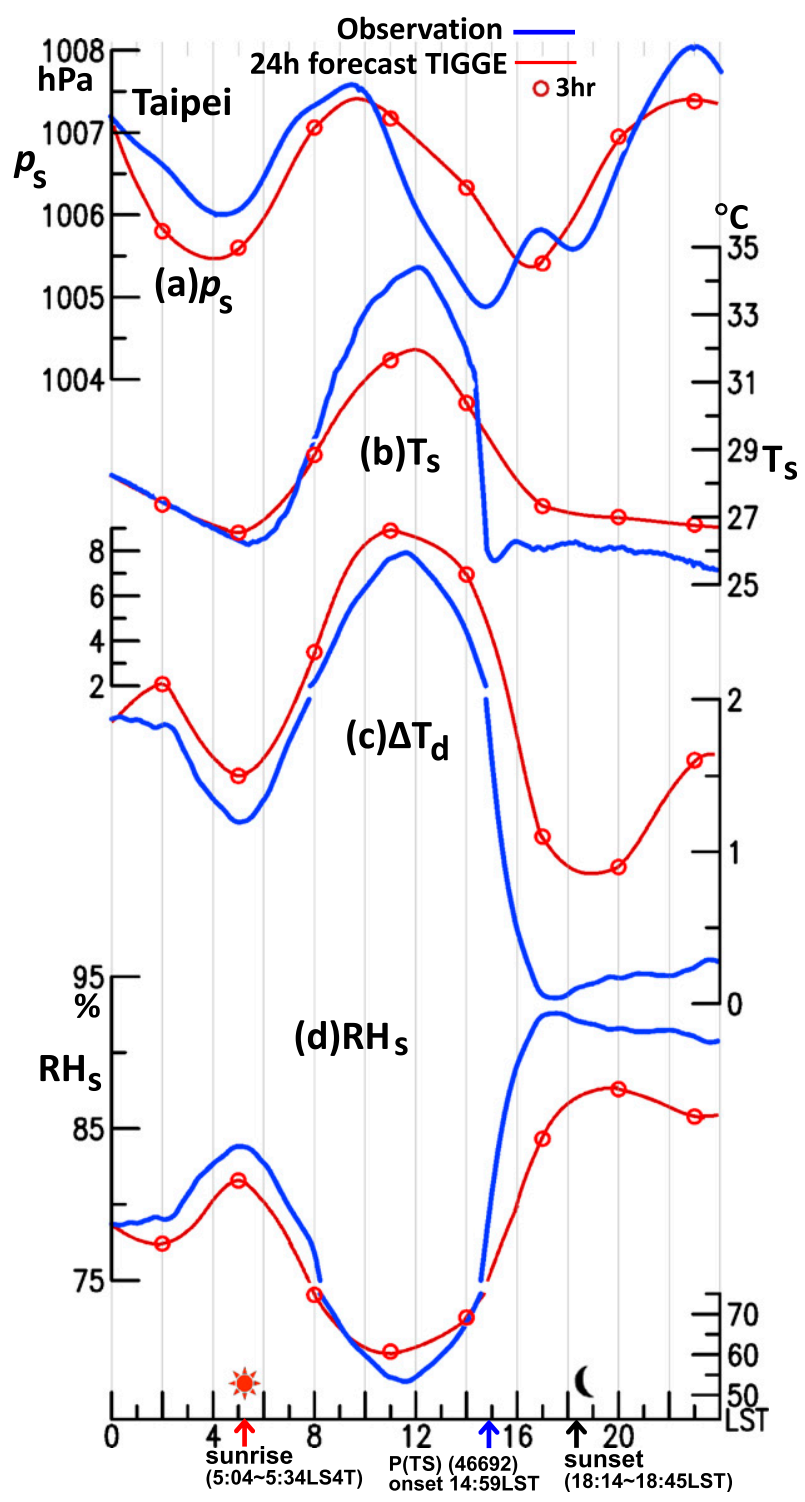

FIG. 8. The composite time series of surface measurements for the meteorological variables at Taipei (WMO 46692) for TS days (blue solid line) and the TIGGE (red solid line) 24-h forecast at $25^{\circ} \mathrm{N}, 121.5^{\circ} \mathrm{E}$, for (a) $p_{s}$, (b) $T_{s}$, (c) $\Delta T_{d}$, and (d) $\mathrm{RH}_{s}$. Red open circles are the model's forecast values at different synoptic times $[1800,2100,0000,0300,0600,0900,1200$, and 1500 UTC (LST - 0800)].

1) The TIGGE day -1 forecasts are replaced by the surface observations in substep 2a, 2c, and 2d.

2) The operational JMA surface synoptic analysis maps and the streamline charts are prepared with the TIGGE initial analysis data issued at 0000 UTC (0800 LST) day 0 . The upper-air $\Delta T_{d}$ and $\mathbf{V}$ profiles are prepared with the 0000 UTC radiosonde measurements made at Panchiao (WMO 46688).

3) One extra requirement is added to step $2 b$ : The sea breeze onset times at exit and mountain stations.
These sea-breeze onset times are determined by the surface $\mathbf{V}$ measured at these stations.

The relay forecast at every substep can be issued when threshold values of criteria (the right-hand column) for items listed in the left-hand column of Figure 11b are met.

Scientifically, this hybrid forecast advisory is developed from the following new findings obtained from the TBEX (C14):

1) The synoptic-scale environment in Southeast/East Asia changes from the cool, dry east/ southeasterly flow across Taiwan on the no-TS day to the warm, moist southwesterly/ southerly flow on the TS day.

2) Diurnal variations of the surface meteorological conditions in the Taipei basin between the TS and no-TS days exhibit distinctive differences in the timings of the minima and maxima of $p_{s}, T_{s}, \Delta T_{d}$, and $\mathrm{RH}_{s}$, and $\mathbf{V}_{s}$.

3) On the no-TS day, the sea-land-breeze transition occurs at sunset, as a result of the longwave radiation cooling of the mountains surrounding the Taipei basin. In contrast, the sea-land-breeze transition on the TS day takes places as soon as the TS rain falls.

Technically, this hybrid forecast advisory for afternoon TS occurrence in the Taipei basin blends the 24-h (day -1) forecast by the high-resolution operational global forecast model (TIGGE) with the relay forecasts for the afternoon TS occurrence with timings of salient features emerging from the diurnal variation of the surface meteorological conditions in the Taipei basin. This hybrid forecast advisory enables the temporalspatial resolution of the state-of-the-art global forecast model to stretch beyond its physical limit to predict the hourly microscale TS occurrence within an urbanscale basin.

The forecast advisory proposed by this study focuses on the forecasting of the afternoon TS occurrence in the Taipei basin with its unique geographic structure. Despite this fact, the synoptic-scale environment and the diurnal variation of the basin-scale surface meteorological conditions observed during this study, in principal, can be applied to explore the relationship of these two meteorological elements with the land-sea-breeze circulation and the afternoon TS activity in other basins/regions with different geographic structures, synoptic-scale environments, surface meteorological conditions, impacts of mountains, and the TS rainfall on the sea-land-breeze transition.

Some recent studies that have appeared in Weather and Forecasting examining different regions have 

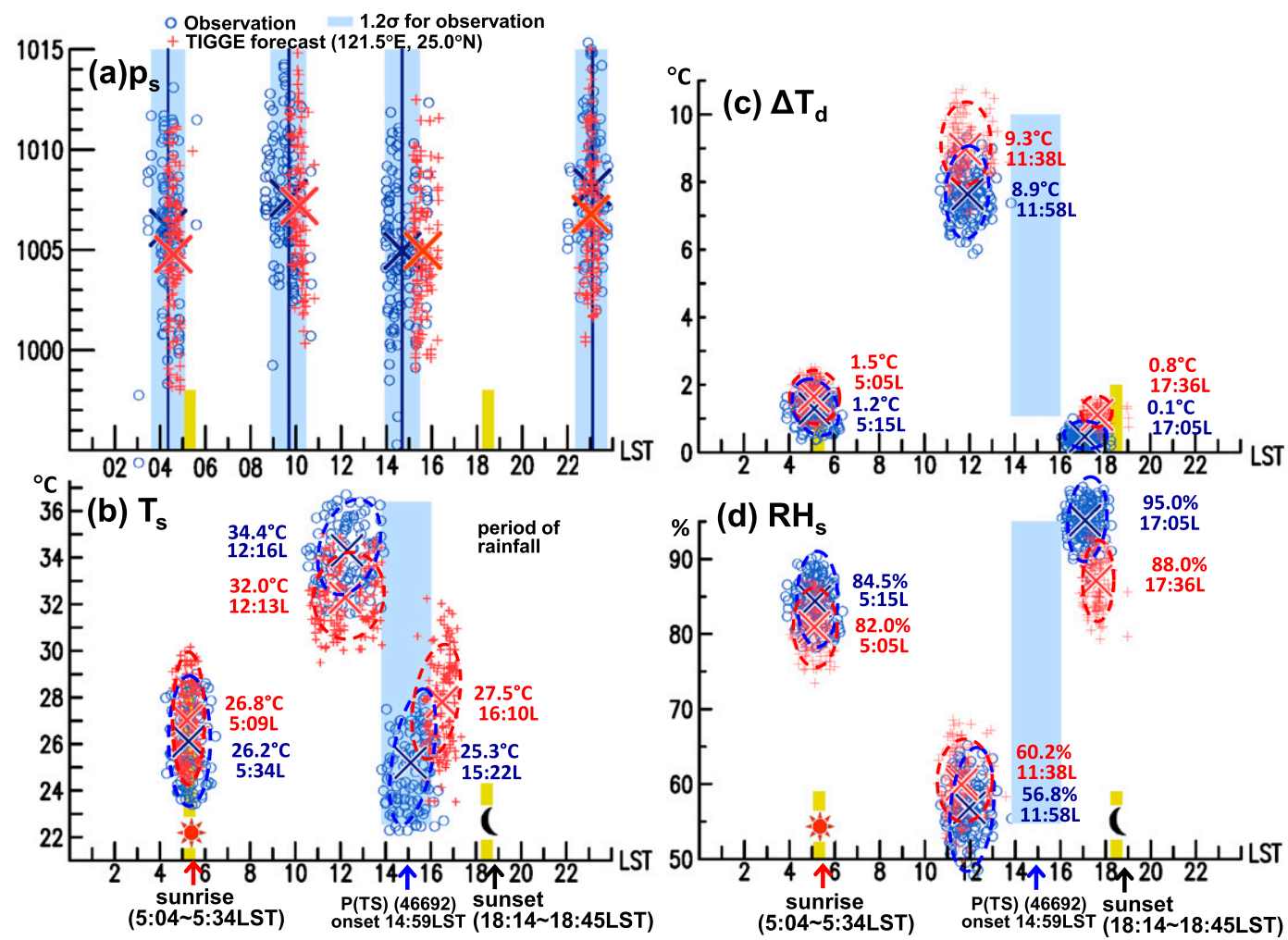

FIG. 9. Maximum/minimum timing for observational and TIGGE results during 141 TS days at Taipei station (WMO 46692). The (a) $p_{s}$, (b) $T_{s}$, (c) $\Delta T_{d}$, and (d) $\mathrm{RH}_{s}$ maximum/minimum timings and values measured by stations for each TS day are denoted by blue open circles, while the corresponding TIGGE 24-h forecast variables are marked by red Greek crosses, respectively. The mean-time value for observations and TIGGE 24-h forecasts are marked by large blue and red crosses, respectively, while 1.2 standard deviations for observation and TIGGE 24-h forecasts are denoted by the blue and red dashed oblongs, respectively. The blue strip in (a) shows the 1.2 standard deviation of $p_{s}$ around its maximum/minimum, and the larger blue strips in (b)-(d) are for the TS rainfall period. The sunrise in early morning and sunset in evening are marked by short yellow strips. The numbers of TS days out of 141 for the four surface variables used to prepare this figure are exactly the same as in Fig. 8. The dashed open ellipse represents one standard deviation computed with the method introduced by Lefever (1926) to generate a standard deviational ellipse.

applied different statistical approaches to forecasting TS occurrence. Manzato (2005) designed a neural network to perform short-term TS forecasts for the Friuli Venezia region in Italy. Schmeits et al. (2008) developed a model output statistics (MOS) scheme to make probabilistic TS forecasts $12 \mathrm{~h}$ in advance for the Netherlands. Using the fuzzy logical algorithm developed by Berenguer et al. (2006), Lin et al. (2012) produced the afternoon TS occurrence probability for the Taipei basin several hours ahead of the afternoon TS occurrence. If the synoptic-scale environment and the basin/region surface meteorological conditions are favorable for the afternoon TS occurrence, the proposed forecast advisory of the present study can be applied to any coastal city in monsoon regions and provide a forecast for afternoon TS occurrence $24 \mathrm{~h}$ in advance.

\section{Validation of forecast advisory}

\section{a. Validation for the two-step forecast advisory}

The two-step forecast advisory for the TS occurrence in the Taipei basin is outlined in section 5. Step 1 of this forecast advisory uses the 24-h forecasts ahead of the TS occurrence day, while step 2 uses observations for the diurnal $\left(p_{s}, T_{s}, \Delta T_{d}, \mathrm{RH}_{s}\right.$, and $\left.\mathbf{V}_{s}\right)$ variations and upperair sounding within the basin. Indices of the synoptic environment around Taiwan and parameters of the surface meteorological conditions in the Taipei basin prior to afternoon TS occurrences are diagnostically analyzed over the 2007-13 period and tabulated in Figure 11 as criteria to validate the forecasts of TS occurrence in 2014 by this forecast advisory. Based on the identification process outlined in section $2 \mathrm{a}, 17 \mathrm{TS}$ days are identified in the Taipei basin. The maximum rainfall 
Two-step procedure of the forecast advisory

for the afternoon thunderstorm in the Taipei basin

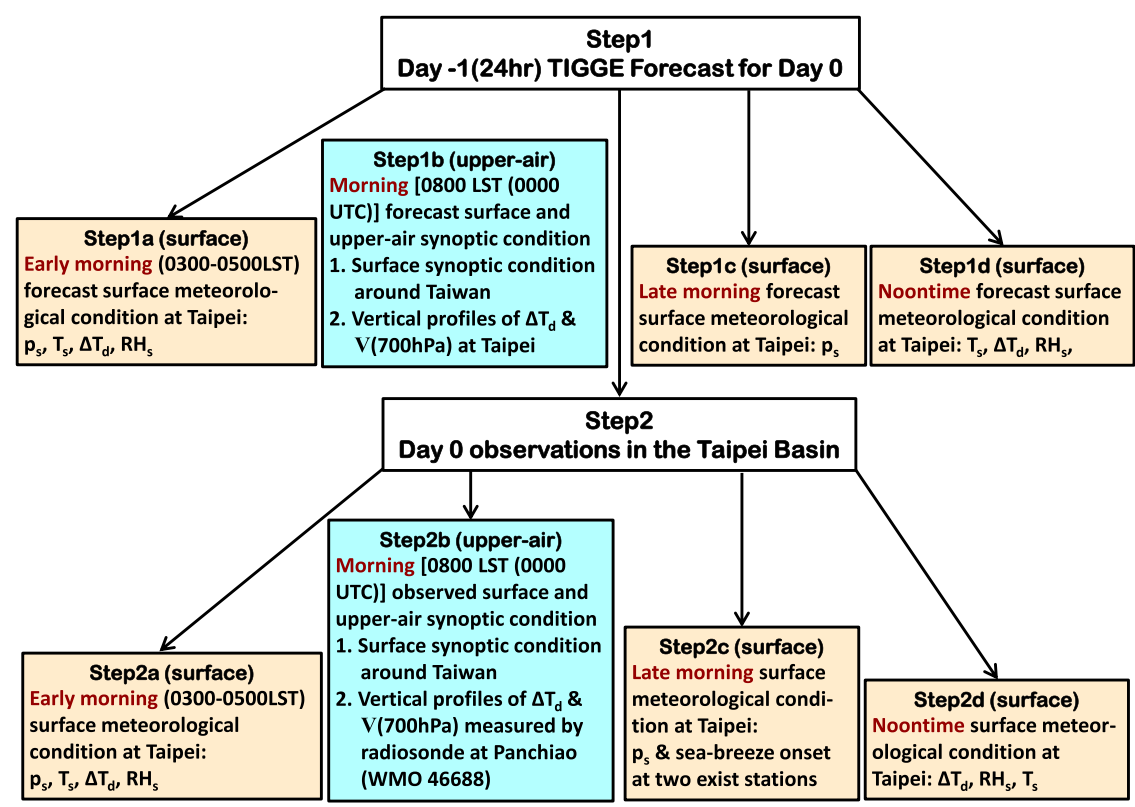

FIG. 10. Validation flowchart of the forecast advisory for the afternoon TS in the Taipei basin. It consists of two steps: 1$)$ day $-1(24 \mathrm{~h})$ TIGGE forecast for the afternoon TS occurrence at day 0 and 2) day 0 observations in the Taipei basin. Each validation step includes four substeps following the timings of the major features emerging from the surface meteorological conditions in the Taipei basin and the synoptic environment with the upper-air soundings at 0800 LST (0000 UTC). Features and criteria of variables at each substep are shown in Figure 11.

rates produced during these TS days and other rainproducing systems are shown in Fig. 12a. The genesis locations defined by rainfall rate during the summer of 2014 are shown in Fig. 12b. A concise validation of this advisory for the TS occurrences in the Taipei basin during the 2014 summer against criteria in Figure 11 is made in this section.

\section{1) STEP 1: DAY -1 (24 H) TIGGE FORECASTS FOR THE DAY 0 SURFACE AND SYNOPTIC CONDITIONS IN THE TAIPEI BASIN}

Day -1 (24h) TIGGE forecasts of the day 0 synoptic environment around Taiwan and the surface meteorological conditions near Taipei for the 17 identified TS days in the 2014 summer are used to validate the step 1 forecasts by the proposed forecast advisory.

(i) Step 1a (early morning), 1c (late morning), and $1 d$ (noontime) criteria

The composite diurnal variations for four TIGGE surface variables $\left(p_{s}, T_{s}, \Delta T_{d}\right.$, and $\left.\mathrm{RH}_{s}\right)$ at Taipei are formed on the 17 TS days with their diurnal variation cycles coinciding in time with the composite over the 2007-13 summers (Fig. 8). Indicated in Figure 11a, the phases/ timings of the early and late morning and noontime extreme (maximum/minimum) values are vital predictors for determining the afternoon occurrences for the next day in the Taipei basin. If only these phases/timings for $p_{s}$, $T_{s}, \Delta T_{d}$, and $\mathrm{RH}_{s}$ are required, the great majority of the identified TS occurrences can be well forecasted a day ahead by TIGGE, as shown in Figs. 13a-d, 13h, and 13i-k.

(ii) Step 1b morning criteria: Synoptic conditions at 0800 LST(0000 UTC)

- Synoptic-Three synoptic conditions around Taiwan at 0800 LST on the TS occurrence day are met by the TIGGE day $-1(24 \mathrm{~h})$ forecast (red dot) for $17 \mathrm{TS}$ days (Fig. 13e).

- Vertical profiles of $\Delta T_{d}$ and $\mathbf{V}$ at Taipei-The 0000 UTC surface $\Delta T_{d}$ criterion at Taipei (Figure 11a) is met by all 17 TIGGE (red dot) 24-h forecasts for day 0 (TS occurrence day) (Fig. 13f). The corresponding $\mathbf{V}(700 \mathrm{hPa})$ results of the TIGGE forecast (red wind barb in Fig. 13g) call for southwesterly flows for all 17 TS days with their averaged speed close to the $\mathbf{V}(700 \mathrm{hPa})$ criterion in Figure 11a.

Based on step 1b, all 17 TIGGE forecasts for the afternoon TS forecast in the Taipei basin met the necessary criteria. 
(a)

\begin{tabular}{|c|c|c|}
\hline Step & Item & $\begin{array}{c}\text { Criteria } \\
\text { (At occurrence Time) }\end{array}$ \\
\hline $\begin{array}{l}\text { Step 1a } \\
\text { (surface) }\end{array}$ & $\begin{array}{l}\text { Early morning (EM; 0300-0500LST) forecasts } \\
\text { surface meteorological conditions } \\
\text { a. } \mathrm{p}_{\mathrm{s}}(\mathrm{TS}) \mathrm{EM} \text { minimum } \\
\text { b. } \mathrm{T}_{\mathrm{s}}(\mathrm{TS}) \mathrm{EM} \text { minimum } \\
\text { c. } \Delta \mathrm{T}_{\mathrm{d}}(\mathrm{TS}) \text { drop with } \mathrm{EM} \text { minimum } \\
\text { d. } \mathrm{RH}_{\mathrm{s}}(\mathrm{TS}) \text { overshooting with maximum }\end{array}$ & $\begin{array}{l}0434 \text { LST } \pm \sigma(28 \mathrm{~min}) \\
0509 \text { LST } \pm \sigma(20 \mathrm{~min}) \\
0505 \text { LST (drop) } \pm \sigma(26 \mathrm{~min}) \\
\text { with an amplitude } 1.6^{\circ} \mathrm{C} \\
0505 \text { LST (overshooting) } \\
\pm \sigma(27 \text { min) with an } \\
\text { amplitude } 2.5 \% \text { increase }\end{array}$ \\
\hline $\begin{array}{l}\text { Step 1b } \\
\text { (synoptics) }\end{array}$ & $\begin{array}{l}\text { 1. Morning [0800LST(0000UTC)] forecast surface and upper-air } \\
\text { synoptic condition } \\
\text { e. }\left\{\begin{array}{l}\text { Cloud/rain free over northern Taiwan } \\
\text { - A NW-SE oriented dipole at } 850-\mathrm{hPa} \text { south of Taiwan* } \\
\text { Southwesterlies straddling the surface low and high of } \\
\text { the dipole }\end{array}\right. \\
\text { 2. Morning [0800LST(0000UTC)] vertical profiles of } \Delta \mathrm{T}_{\mathrm{d}} \text { and } \\
\text { V(700hPa) at Taipei } \\
\left\{\begin{array}{l}\text { f. } \Delta \mathrm{T}_{\mathrm{d}}(\mathrm{TS}) \text { at surface and } 500 \mathrm{hPa} \text {; slightly larger than the } \\
\text { observed TS days } \\
\text { g. } \mathrm{V}_{\mathrm{TS}}(700 \mathrm{hPa}) \text {; southwesterly }\end{array}\right.\end{array}$ & $\begin{array}{l}\text { yes/no } \\
\text { yes/no } \\
\text { yes/no } \\
\\
2.8^{\circ} \mathrm{C} \pm \sigma\left(0.9^{\circ} \mathrm{K}\right) \& \\
9.7^{\circ} \mathrm{C} \pm \sigma\left(2.6^{\circ} \mathrm{K}\right) \\
5.1 \mathrm{~m} \cdot \mathrm{s}^{-1} \pm \sigma\left(3.7 \mathrm{~m} \mathrm{~s}^{-1}\right)\end{array}$ \\
\hline $\begin{array}{c}\text { Step 1c } \\
\text { (surface) }\end{array}$ & $\begin{array}{l}\text { Late morning (LM) forecasts } \\
\text { h. } \mathrm{p}_{\mathrm{s}}(\mathrm{TS}) \text { LM maximum }\end{array}$ & 1008 LST $\pm \sigma(42 \mathrm{~min})$ \\
\hline $\begin{array}{l}\text { Step 1d } \\
\text { (surface) }\end{array}$ & $\begin{array}{l}\text { Noontime (NT) forecasts } \\
\text { i. } \Delta \mathrm{T}_{\mathrm{d}}(\mathrm{TS}) \text { NT maximum } \\
\text { j. } \mathrm{RH}_{\mathrm{s}}(\mathrm{TS}) \text { NT minimum } \\
\text { k. } \mathrm{T}_{\mathrm{s}}(\mathrm{TS}) \text { NT maximum }\end{array}$ & $\begin{array}{l}1138 \text { LST } \pm \sigma(40 \mathrm{~min}) \\
1138 \text { LST } \pm \sigma(38 \mathrm{~min}) \\
1213 \text { LST } \pm \sigma(55 \mathrm{~min})\end{array}$ \\
\hline
\end{tabular}

(b)

2007-2013

\begin{tabular}{|c|c|c|}
\hline Step & Item & $\begin{array}{c}\text { Criteria } \\
\text { (At occurrence Time) }\end{array}$ \\
\hline $\begin{array}{l}\text { Step 2a } \\
\text { (surface) }\end{array}$ & $\begin{array}{l}\text { Early morning (EM; 0300-0500LST) surface meteorological } \\
\text { condition at Taipei } \\
\text { I. } p_{s}(T S) E M \text { minimum } \\
\text { m. } T_{s}(T S) \text { EM minimum } \\
\text { n. } \Delta T_{d}(T S) \text { drop with EM minimum } \\
\text { o. } R H_{s}(T S) \text { maximum/overshooting }\end{array}$ & $\begin{array}{l}0412 \text { LST } \pm \sigma(30 \mathrm{~min}) \\
0534 \text { LST } \pm \sigma(20 \mathrm{~min}) \\
0515 \text { LST (drop) } \pm \sigma(34 \mathrm{~min}) \\
\text { with a drop } \sim 1.2^{\circ} \mathrm{C} \\
0515 \text { LST (overshooting) } \\
\pm \sigma(32 \text { min) with an } \\
\text { increase } \sim 5.0 \%\end{array}$ \\
\hline $\begin{array}{c}\text { Step 2b } \\
\text { (synoptics) }\end{array}$ & $\begin{array}{l}\text { 1. Morning [0800LST(0000UTC)] observed surface and } \\
\text { upper-air synoptic condition } \\
\text { p. }\left\{\begin{array}{l}\text { Cloud-rain/free over northern Taiwan } \\
\text { - A NW-SE oriented dipole at } 850 \mathrm{hPa} \text { south of Taiwan* } \\
\text { - Southwesterlies straddling the surface low and high of } \\
\text { the dipole }\end{array}\right. \\
\text { 2. Morning [0800LST(0000UTC)] vertical profile of } \Delta \mathrm{T}_{\mathrm{d}} \& \mathrm{~V}(700 \\
\text { hPa) measured by radiosonde at Panchiao (WMO } 46688) \\
\left\{\begin{array}{l}\text { q. } \Delta \mathrm{T}_{\mathrm{d}}(\mathrm{TS}) \text { at surface and } 500 \mathrm{hPa} \\
\text { r. } \mathrm{V}_{\mathrm{TS}}(700 \mathrm{hPa})\end{array}\right.\end{array}$ & $\begin{array}{l}2.1^{\circ} \mathrm{C} \pm \sigma\left(0.8^{\circ} \mathrm{K}\right) \& \\
8.3^{\circ} \mathrm{C} \pm \sigma\left(2.4^{\circ} \mathrm{K}\right) \\
6.0 \mathrm{~m} \cdot \mathrm{s}^{-1} \pm 4.2 \mathrm{~m} \cdot \mathrm{s}^{-1}\end{array}$ \\
\hline \multirow{3}{*}{$\begin{array}{l}\text { Step 2c } \\
\text { (surface) }\end{array}$} & $\begin{array}{l}\text { Late morning }(\mathrm{LM}) \text { surface meteorological condition along two } \\
\text { river valleys } \\
\text { s. } p_{\mathrm{s}}(\mathrm{TS}) \text { LM maximum at exit station (\#1) and mountain slope } \\
\text { station (\#6) }\end{array}$ & 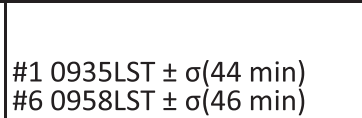 \\
\hline & \multirow[t]{2}{*}{$\begin{array}{l}\text { t. Sea breeze onset at exit stations (\#1 and \#7), } \\
\text { SB onset at mountain slope station (\#6 and 12). }\end{array}$} & $\begin{array}{l}\# 1: 0952 L S T \pm \sigma(58 \mathrm{~min}) \\
\# 6: 1020 L S T \pm \sigma(1 \mathrm{~h} 10 \mathrm{~min})\end{array}$ \\
\hline & & $\begin{array}{l}\# 7: 0952 L S T \pm \sigma(51 \mathrm{~min}) \\
\# 12: 1024 \mathrm{LST} \pm \sigma(1 \mathrm{~h} 4 \mathrm{~min})\end{array}$ \\
\hline $\begin{array}{l}\text { Step 2d } \\
\text { (surface) }\end{array}$ & $\begin{array}{l}\text { Noontime (NT) surface meteorological condition at Taipei } \\
\text { u. } \Delta \mathrm{T}_{d}(T S) \text { NT maximum } \\
\text { v. } \mathrm{RH}_{\mathrm{s}}(\mathrm{TS}) \text { NT minimum } \\
\text { w. } \mathrm{T}_{s}(\mathrm{TS}) \text { NT maximum }\end{array}$ & $\begin{array}{l}1158 \mathrm{LST} \pm \sigma(35 \mathrm{~min}) \\
1158 \mathrm{LST} \pm \sigma(36 \mathrm{~min}) \\
1216 \mathrm{LST} \pm \sigma(54 \mathrm{~min})\end{array}$ \\
\hline
\end{tabular}

* South of a ridge line with southwesterlies + confirmed by the V(850 hPa) streamline chart

FIG. 11. Criteria for TS occurrence (a) Step 1 day -1 (24 h) TIGGE forecast for day 0 (2007-13) and (b) Step 2 day 0 observations in the Taipei basin. 

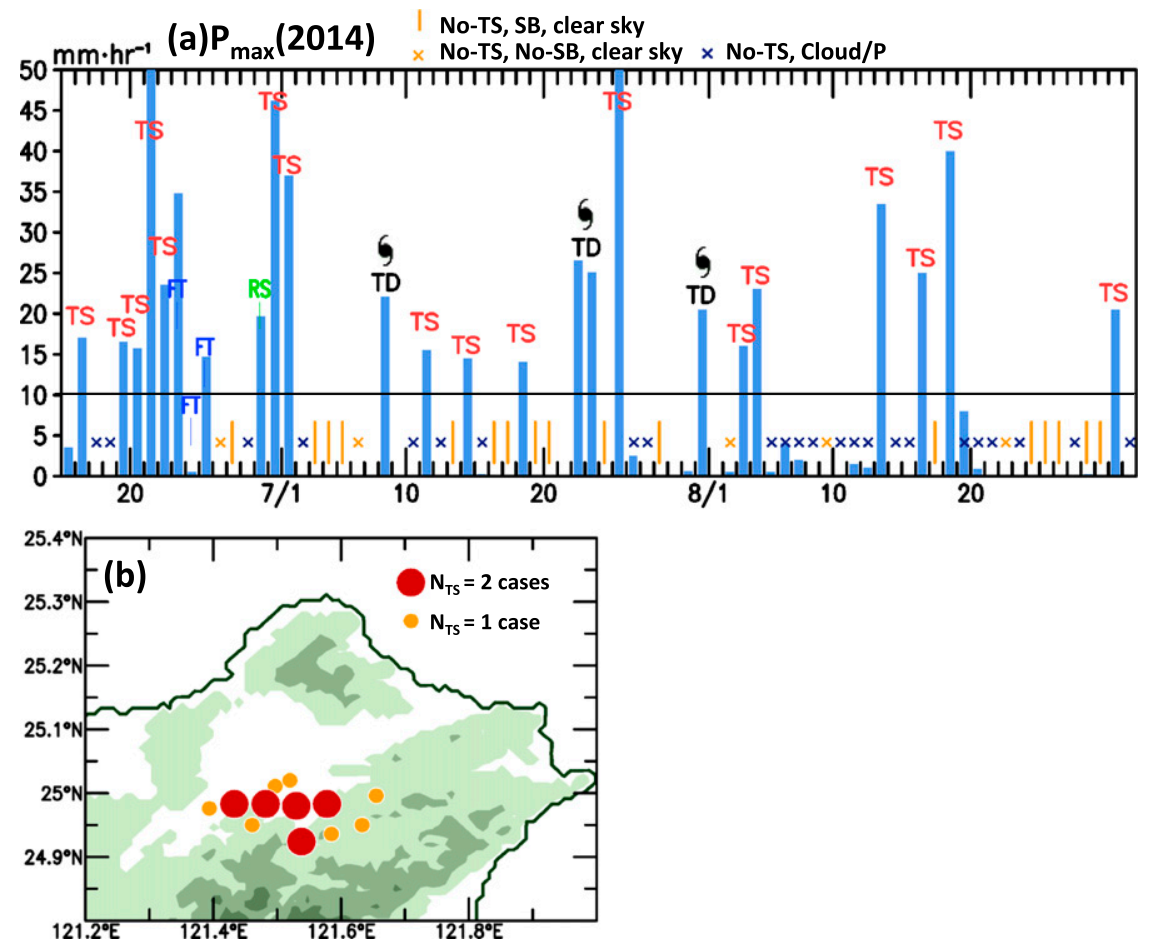

FIG. 12. (a) Rainfall histogram of the maximum afternoon TS rainfall rate measured by surface stations during summer 2014. Rainfall rates of other weather systems (FT, RS, and TD) are determined by their maximum values within 1400-1800 LST. (b) Locations of TS genesis identified by surface stations within the Taipei basin for rain rate $\geq 10 \mathrm{~mm} \mathrm{~h}^{-1}$.

2) STEP 2: DAY 0 FORECAST BASED ON OBSERVATIONS OF SYNOPTIC AND SURFACE METEOROLOGICAL CONDITIONS IN THE TAIPEI BASIN

The procedure developed in step 2 essentially follows the timings of the salient features in the diurnal variations for $p_{s}, T_{s}, \Delta T_{d}, \mathrm{RH}_{s}$, and $\mathbf{V}_{s}$ in the Taipei basin. To avoid redundancy, only station 1 (river-exit station) and station 6 (mountain slope station) along the Tanshui River valley are used to demonstrate the validation for step 2. Synoptic conditions of Southeast/ East Asia, depicted by the JMA surface analysis and the $850-\mathrm{hPa}$ streamline charts superimposed with IR/TRMM data, and the upper-air soundings at Taipei at 0000 UTC (0800 LST) are also applied in step 2's validation.

(i) Step 2a: Early morning criteria for $p_{s}$ and $T_{s}$ minima, $\Delta T_{d}$ drop, and $\mathrm{RH}_{s}$ overshooting at Taipei

Timing criteria for $p_{s}$ (TS) and $T_{s}$ (TS) minima, $\Delta T_{d}$ drop, and $\mathrm{RH}_{s}$ (TS) overshooting (Figure 11b) met by occurrences of early morning $p_{s}$ (TS) and $T_{s}$ (TS) minima, $\Delta T_{d}$ minor minimum, and $\mathrm{RH}_{s}$ minor maximum at Taipei for all TS days are shown in Figs. 131-o. (ii) Step 2b: Morning criteria for the synoptic conditions at 0800 LST (0000 UTC)

- Synoptics-The three synoptic conditions, as required by step $1 \mathrm{~b}$, are validated by the JMA surface analysis maps and $850-\mathrm{hPa}$ streamline charts [constructed with TIGGE $\mathbf{V}(850 \mathrm{hPa})]$ superimposed with IR/TRMM. Shown in Fig. 13p, the three required synoptic conditions are met by all 17 TS days during 2014.

- Vertical profiles of $\Delta T_{d}$ and $\mathbf{V}$ are measured by radiosonde at Panchiao.

The environment favorable for TS occurrence is developed by the warm, moist air mass transported by the southwesterly monsoon flow across the Taipei basin. As shown in Figs. 13q and 13r, the required magnitudes for $\Delta T_{d}$ (surface) and $\left|\mathbf{V}_{\mathrm{TS}}(700 \mathrm{hPa})\right|$, as well as the flow directions for $\mathbf{V}_{\mathrm{TS}}(700 \mathrm{hPa})$ listed in Figure $11 \mathrm{~b}$, are satisfied by all 17 TS days at 0000 UTC.

(iii) Step 2c: Late-morning criteria for $p_{s}$ maximum at Taipei and $S B$ onsets along the river valleys

In the late morning of the TS day, the $p_{s}$ (TS) maximum at station 1 (left panel of Fig. 13s), at close to 1000 LST, is about a half hour ahead of the $p_{s}$ (TS) maximum at station 6 (right panels of Fig. 13s). The SB onset times 
Step1 Day -1(24hr) TIGGE Forecast for Day

Step1a: Early morning criteria

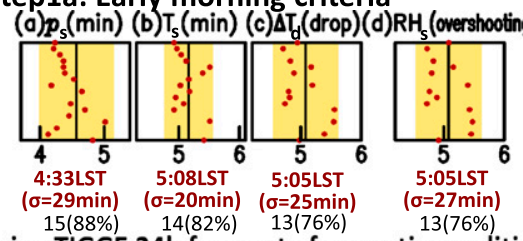

Step1b morning criteria : TIGGE $24 \mathrm{~h}$ forecast of synoptic condition at 0800LST(0000UTC)

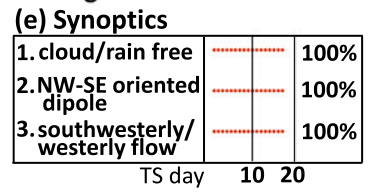

(f) $\Delta T_{d}$ (TS)

(g) $\mathrm{V}(700 \mathrm{hPa})$

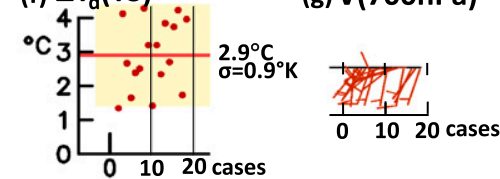

Step1c: Late morning criteria Step1d: Noontime criteria

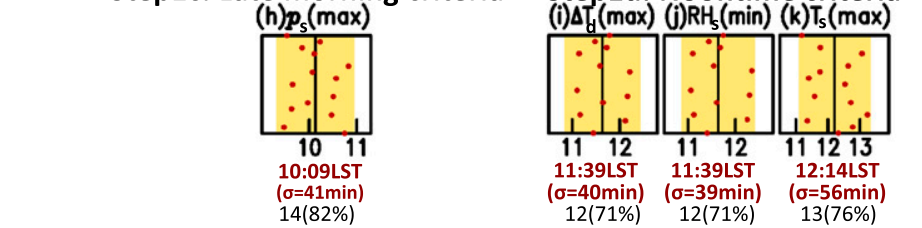

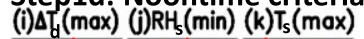

Step2 Day 0 Forecast based on observation in the Taipei Basin Step2a Early morning criteria at Taipei (I) $\boldsymbol{p}_{\mathrm{s}}(\mathrm{min})(\mathrm{m}) \mathrm{T}_{\mathrm{s}}(\mathrm{min})(\mathrm{n}) \Delta \mathrm{T}_{\mathrm{d}}$ (drop) (o)RH (overshooting)
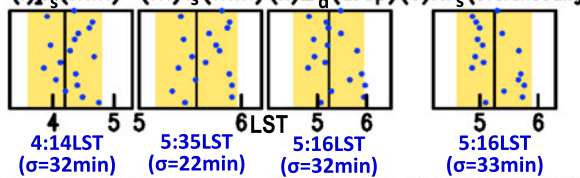

Step2b Morning criteria [synoptic condition \& sounding(WMO 46688) at 0800LST(0000UTC)]

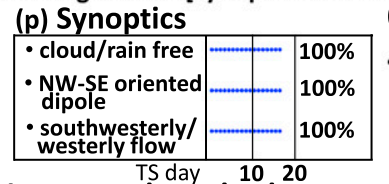

Step2c Late morning criteria
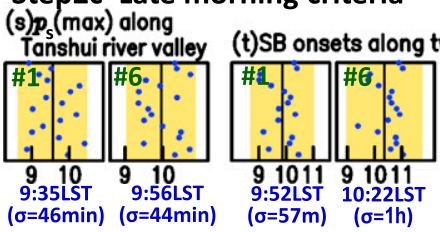

(q) $\Delta T_{d}(T S)$

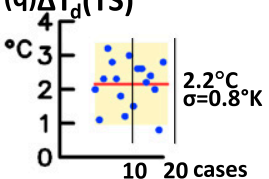

Step2d noontime criteria at Taipei (u) $\Delta \tau_{\mathrm{t}}(\max )(\mathrm{v}) \mathrm{RH}_{5}(\min )(w) \tau_{s}(\max )$ (r) $\mathrm{V}(700 \mathrm{hPa})$
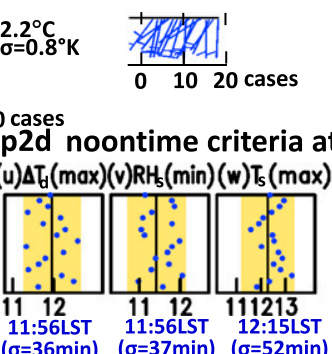

FIG. 13. Validation of the forecast advisory forecasting 17 afternoon TS occurrences in the Taipei basin during 15 Jun-31 Aug 2014. Validation of step 1 for the 24-h TS forecast by TIGGE consists of four substeps: 1a) the early morning criteria for the timings of (a) $p_{s}$ (minimum), (b) $T_{s}$ (minimum), (c) $\Delta T_{d}$, and (d) $\mathrm{RH}_{s}$ overshooting at a grid point $\left(25^{\circ} \mathrm{N}, 121.5^{\circ} \mathrm{E}\right)$ for $\mathrm{TS}$ days; 1b) morning (0000 UTC) synoptics for (e) three synoptic conditions, (f) dewpoint depression $\Delta T_{d}$, and $(\mathrm{g}) 700$-hPa wind vector $\mathbf{V}(700 \mathrm{hPa})$ at a grid point $\left.\left(25^{\circ} \mathrm{N}, 121.5^{\circ} \mathrm{E}\right) ; 1 \mathrm{c}\right)$ late morning criteria for the timing of (h) $p_{s}$ (maximum); and 1d) the noontime criteria for timings of (i) $\Delta T_{d}$ (maximum), (j) $\mathrm{RH}_{s}$ (minimum), and (k) $T_{s}$ (minimum). Validation of step 2 for the diurnal variation of surface meteorological variables also consists of four substeps: $2 \mathrm{a}$ ) early morning criteria for timings of (l) $p_{s}$ (minimum), (m) $T_{s}$ (miniumum), (n) $\Delta T_{d}$, and (o) $\mathrm{RH}_{s}$ overshooting at Taipei for $17 \mathrm{TS}$ days; 2b) morning (0000 UTC) synoptics for (p) three synoptic conditions, (q) $\Delta T_{d}$, and (r) V(700 hPa) measured by the upper-air soundings at Panchiao (WMO 46688); 2c) late-morning criteria for the timing of (s) $p_{s}$ (maximum) along the Tanshui River valley at exit station 1 (Tanshui) and mountain slope station 6 (Jin-me) and (t) sea-breeze onset time at exit stations 1 (Tanshui) and 7 (Keelung), along with mountain slope stations 6 (Jin-me) and 12 (Panchiao); and 2d) the noontime criteria for the timings of (u) $\Delta T_{d}$ (maximum), (v) $\mathrm{RH}_{s}$ (minimum), and (w) $T_{s}$ (maximum). Yellow strips show 1.2 standard deviations. Numerical values shown at the bottoms of figures presented in steps 1a, 1c, and 1d include averaged timings of $p_{s}, T_{s}, \Delta T_{d}$, and $\mathrm{RH}_{s}$ ) maxima/minimum (first row), standard deviations $\sigma_{s}$ of the average timings (second row), numbers of TS days used (third row), and percentage of TS days used against the total number of TS days (17 days for TIGGE). 
TABLE 2. Days with different weather conditions (last column) occurring within the Taipei basin during the period of 15 Jun-31 Aug 2014 . The * indicates a contribution from the North Pacific upper-level vortex.

\begin{tabular}{|c|c|c|c|}
\hline \multicolumn{2}{|c|}{ Group } & Weather system/conditions & \multirow{2}{*}{$\frac{\text { No. of days }}{17}$} \\
\hline $\mathrm{a}$ & a1 & $\mathrm{TS}, \mathrm{SB}$, afternoon/evening rainfall & \\
\hline & (b1-b3) & TS, no SB, rain: external synoptic systems (RS, FT, TC) & $(15)$ \\
\hline & $\mathrm{a} 2(\mathrm{~b} 4 *)$ & No TS, SB, clear sky & $17(1 *)$ \\
\hline & a3 & No TS, SB, cloud/rain $\left(<10 \mathrm{~mm} \mathrm{~h}^{-1}\right)$ & 24 \\
\hline & $\mathrm{a} 4(\mathrm{~b} 4 *)$ & No TS, no SB, clear sky & $5(1 *)$ \\
\hline \multirow[t]{11}{*}{$\mathrm{b}$} & b1 & Rainstorm (RS) & 1 \\
\hline & b2 & Front location & \\
\hline & & $\leq 50 \mathrm{~km}$, rain at Taipei, no SB & 3 \\
\hline & & $>50 \mathrm{~km}$, rain at Taipei, SB & 0 \\
\hline & & $>50 \mathrm{~km}$, rain at Taipei, no SB & 0 \\
\hline & b3 & $\mathrm{TC}$ & \\
\hline & & $|\mathbf{V}| \geq 35 \mathrm{kt}$ with rain & 6 \\
\hline & & $|\mathbf{V}| \geq 35 \mathrm{kt}$ with no rain and no SB & 4 \\
\hline & & $|\mathbf{V}|<35 \mathrm{kt}$ with rain, TC center $>300 \mathrm{~km}$ from Taipei & 0 \\
\hline & & $|\mathbf{V}|<35 \mathrm{kt}$ with no rain and no SB, TC center $>300 \mathrm{~km}$ from Taipei & 1 \\
\hline & $\mathrm{b} 4 *$ & North Pacific upper-level vortex & 2 \\
\hline
\end{tabular}

at both the exit and mountain slope stations in the two river valleys (Fig. 12t) follow the $p_{s}$ (TS) maxima and occur close to 1000 and 1030 LST, respectively, as in Fig. 12t. These two salient features for all TS days occur close to the criteria set forth in Figure $11 \mathrm{~b}$.

(iv) Step 2d: Noontime criteria for $T_{s}$ and $\Delta T_{d}$ maxima, and $\mathrm{RH}_{s}$ minimum at Taipei

The final check of all TS days satisfying the criteria from steps $2 \mathrm{~b}-\mathrm{d}$ is performed to ascertain whether the $\Delta T_{d}$ (TS) noontime maximum and the $\mathrm{RH}_{s}$ (TS) noontime minimum occurred at $1158 \mathrm{LST}$, and the $T_{s}$ (TS) noontime maximum occurred at 1216 LST before the afternoon thunderstorm occurrence during 1430-1600 LST. The occurrence timings of the $\Delta T_{d}$ (TS) maximum and the $\mathrm{RH}_{s}$ (TS) minimum, as well as the $T_{s}$ (TS) maximum, at station 1 are about a half hour earlier than at station 6, as shown in Figs. 13u-w. The $\Delta T_{d}$ (TS) maximum and $\mathrm{RH}_{\mathrm{s}}$ (TS) minimum, and the $T_{s}$ (TS) maximum, take place at least $2-3 \mathrm{~h}$ prior to the occurrence of the afternoon thunderstorm.

\section{b. Alternative validation}

Shown in Table 2, the 2014 summer weather systems observed in the Taipei basin include two more groups, in addition to the TS and no-TS (with SB and clear sky) groups. These two groups are 1) synoptic systems (rainstorm, front, typhoon, and North Pacific upper-level vortex) and 2) basin-scale weather systems (no-TS, no-SB, clear sky and no-TS, SB, cloud/rain). Over the 2007 summer period, the former group contributes 15 days, and the latter group covers 29 days. Additionally, the no-TS, SB, clear-sky weather systems claim 17 days. One may question whether the identification/forecast of TS days in section $6 a$ is sufficiently stringent. This concern may be clarified by two alternative methods devised to confirm the forecast made by the 24 -h simulation for day -1 :

1) The first alternative method to validate the identification of the basin-scale weather system is to test whether they meet the validation criteria for the TS forecast advisory. This validation was conducted with three subgroups of the basin-scale weather systems listed in Table 2 . This is an alternative way to check for any missing TS days. As shown in Fig. 14, no single day for these three subgroups of the basin-scale weather systems can satisfy the validation criteria for the TS day. Note that the synoptic systems affecting the basin-scale weather can be classified.

2) The second alternative method for validating the identification of the synoptic systems and the basinscale weather systems can be conducted by the following approaches: identify (i) the no-TS, SB, clear-sky basin-scale weather system presented in the first group of section $2 \mathrm{a}(1)$ and (ii) the weather systems other than the TS and no-TS, SB, clear-sky conditions outlined in the second group of section $2 \mathrm{a}(2)$. In fact, the classification of all summer weather systems for the 2014 summer was performed and is shown in Table 2.

\section{Concluding remarks}

Summer is a dry season in northern Taiwan. By contrast, the Taipei basin, which is located in this region, has unique orographic characteristics that produce maximum rainfall during summer; $78 \%$ of this rainfall is contributed by afternoon thunderstorms. The afternoon TS activity, on average, begins on 15 June in the Taipei basin, but the afternoon TS occurrence covers only about 
(a) No-TS, SB, cloud/rain free

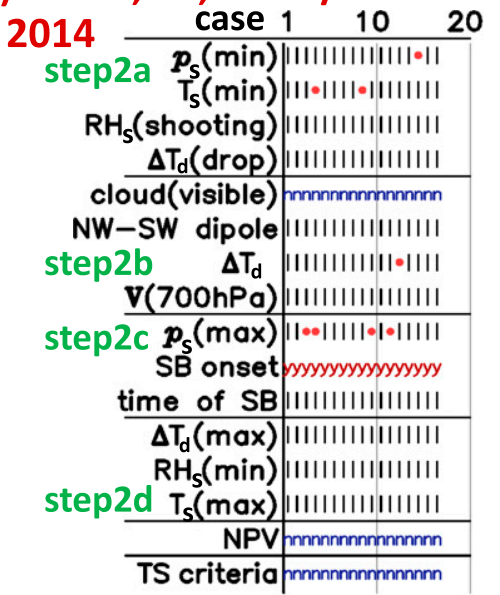

$$
\begin{aligned}
& \text { । : TS criteria not met } \\
& \text {-: TS criteria met } \\
& y: \text { yes } \\
& n: \text { no }
\end{aligned}
$$

(b)No-TS, no-SB case 15

step2a \begin{tabular}{c|c}
$\boldsymbol{p}_{\mathbf{s}}(\min )$ & $\|\bullet\| 1$ \\
$\mathrm{~T}_{\mathbf{s}}(\min )$ & $\|1\| 1$
\end{tabular} $\mathrm{RH}_{\mathrm{s}}$ (shooting) $\| 11$. $\Delta T_{d}$ (drop) $111{ }^{\circ}$ cloud(visible) innnn ridge 11111 step2b $\quad \Delta T_{d} \quad I I I I$ $\mathbf{v}(700 \mathrm{hPa}) 11.11$ step2c $\boldsymbol{p}_{\boldsymbol{s}}$ (max) 11111 SB onset hnnn time of SB IIIII $\Delta T_{d}(\max ) \mid I I I I$ $\mathrm{RH}_{\mathrm{s}}(\mathrm{min}) \| 1111$ step2d $\mathrm{T}_{\mathbf{s}}$ (max) IIIII NPV innnn TS criteria innnn
(c)No-TS, SB, cloud/P $\begin{array}{lll}\text { case } 1 & 10 \quad 20\end{array}$ step2a $\boldsymbol{p}_{\mathbf{s}}(\min )\left|\left\||||||-||||||||| \cdot|\||||^{\circ}\right.\right.$ $\mathrm{RH}_{s}$ (shooting) ||||||$\cdot|1 \cdot 0 \cdot 1 \cdot| 1 \cdot 1 \cdot 1||||$. $\Delta T_{d}$ (drop) $111111 \cdot 11 \cdot 01 \cdot 11 \cdot 1 \cdot 111111$

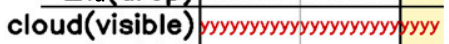
ridge $|\cdot| 1|1| \cdot \bullet|1 y y| 1 \cdot 1 y \bullet 0111 \cdot$ step2b $\quad \Delta T_{d}$ IIIIIIIIIIIIIIIIIII $\mathbf{v}(700 \mathrm{hPa}) \mid 111 \cdot 1 \cdot 1 \cdot 1 \cdot 111 \cdot 111 \cdot 0 \cdot 1 \cdot 1 \cdot$ step2c $\boldsymbol{p}_{\mathbf{s}}(\max )|1 \cdot 1||||||||\cdot||||||||||| \mid$ sea breeze pyyyyyyyyysyyyyyyyy pyyy

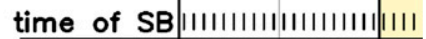

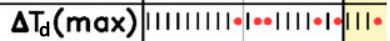
$\mathrm{RH}_{\mathrm{s}}(\min ) \mid 11111111.1001111 .101110$

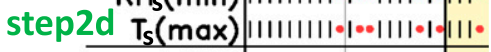

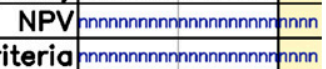

FIG. 14. Validation for step 2 of the proposed forecast advisory for (a) no-TS day, SB, and cloud/rain free; (b) noTS, no-SB day; and (c) no-TS, SB, cloud/precipitation day during 15 Jun-31 Aug 2014; no TS day is missing from the identification process. The measured variable meeting the criteria of a TS is denoted by a red dot; otherwise, a short black line is used. The existence of a required phenomenon is denoted by a " $y$ "; otherwise, it is denoted by "n." The final results are shown in the last row (TS criteria); if the forecast results predict a TS, a y is used; otherwise, an $n$ is used. NPV in the second item from the bottom represents the North Pacific upper-level vortex (Chen et al. 2001).

20 days ( $\sim 26 \%$ ) out of 78 summer (15 June-31 August) days. These few days account for $78 \%$ of the summer rainfall. This rainfall vitally affects the well-being of about three million people in a number of aspects: water supply, traffic hazards, cleaning of the basin's air pollution, urban planning, and ground subsidence. Forecasting afternoon TS activity is a crucial issue for the local government. Because the size $(30 \mathrm{~km} \times 60 \mathrm{~km})$ of the Taipei basin is small, the development of a forecast model for such a small basin is a great challenge impacted by various factors: the temporalspatial resolution, the coupling between regional and urban forecast models, the proper consideration of the orographic forcing, the differential radiative effects between the basin and surrounding mountains, the basin's interaction of the UHI and orography with the land-sea breeze and ambient monsoon flow, the impact of the basin's land-sea-breeze circulation by the mountains surrounding the basin, the TS activity, etc.

Previous studies of TS occurrence frequency impacted by the UHI effect (Chen et al. 2007) and the classification of weather systems in the Taipei basin that search for the systematic difference in the synoptic conditions and the basic characteristics of the land-sea breeze between TS and no-TS days (C14) led us to develop a two-step hybrid forecast advisory for the TS occurrence in this basin. The TS occurrence will take place in the afternoon, if all requirements for this forecast advisory are met. The $141 \mathrm{TS}$ days identified for the 2007-13 period were successfully validated by this two-step forecast advisory. Despite this success, two alternative methods are also adopted to further confirm this validation by testing whether other identified group weather systems, in addition to the TS group, meet the TS occurrence criteria, and by identifying the no-TS, SB, clear-sky basin-scale weather system and the weather systems other than the TS and the no-TS, SB, clear-sky groups.

The current Taiwan CWB's statistical forecast approach for afternoon TS occurrence in the Taipei basin utilizes measurements of surface variables and upper-air soundings (at 0000 UTC) over the 0800-1200 LST time windows to issue its forecast at 1030 LST (Lin et al. 2012). By contrast, the forecast advisory developed by the present study can issue the forecast for the potential afternoon TS occurrence in the basin a day $(24 \mathrm{~h})$ in advance, following the step 1 procedure of this advisory. This $24-h$ TS occurrence forecast can be updated, following this advisory's step 2 procedure on day 0 with the upper-air synoptic conditions measured by the 0000 UTC upper-air sounding and characteristics of surface variables modulated by the sea breeze in the early morning (0500 LST) and late morning (1030 LST), and at noontime. Instead of adopting the conventional approach to generate forecasts with initial conditions, the relay of the day -1 operational forecast by updating with the day 0 diurnal variation features of surface variables in the basin, which predicts the afternoon 
TS occurrence with a 24-h lead, is an innovative approach to developing forecast advisories.

The development of this advisory relies on observations of synoptic features and diurnal variations of the SB characteristics to provide us with clues about the dynamics of high importance to thunderstorm formation for this unique orographic situation. The advantage of this forecast advisory is its implementation without additional computer modeling, which might be expensive or reduce the lead time for the forecast. However, this advisory is not operationally free of any hurdles. The success in providing a timely forecast advisory for the TS occurrence is crucially dependent upon the timely supply of necessary day $-124-\mathrm{h}$ operational forecasts and the day 0 surface observations along two river valleys, Tanshui and Keelung, in the Taipei basin. This potential operational hindrance of the data supply can be resolved by careful and systematic coordination between the two steps of the advisory. Additionally, the classification of weather systems and weather conditions in the Taipei basin, as well as the validation process for this advisory, are cumbersome tasks. Because this advisory does not require any additional measurement network expansion to implement some of the key elements of this advisory, the concerns raised here can be automated by use of pattern recognition, expert systems, or other computer-based evaluations of the day 0 observations.

Acknowledgments. This study was sponsored by the Cheney Research Fund and NSF Grant ATM-0836220. We thank two reviewers and Philip Schumacher for their constructive and helpful comments and suggestions to improve this paper.

\section{REFERENCES}

Berenguer, M., D. Sempere-Torres, C. Corral, and R. SánchezDiezma, 2006: A fuzzy logic technique for identifying nonprecipitating echoes in radar scans. J. Atmos. Oceanic Technol., 23, 1157-1180, doi:10.1175/JTECH1914.1.

Bougeault, P., and Coauthors, 2010: The THORPEX Interactive Grand Global Ensemble (TIGGE). Bull. Amer. Meteor. Soc., 91, 1059-1072, doi:10.1175/2010BAMS2853.1.

Bui, R., R. N. Buliung, and T. K. Remmel, 2012: A collection of functions for estimating centrographic statistics and computational geometries for spatial point patterns, version 3.2. Comprehensive R Archive Network, 35 pp. [Available online at http://cran.r-project.org/web/packages/aspace/aspace.pdf.]

Chen, T.-C., M.-C. Yen, J.-C. Hsieh, and R. W. Arritt, 1999: Diurnal and seasonal variations of the rainfall measured by the Automatic Rainfall and Meteorological Telemetry System in Taiwan. Bull. Amer. Meteor. Soc., 80, 2299-2312, doi:10.1175/ 1520-0477(1999)080<2299:DASVOT>2.0.CO;2.

—_ - — , G.-R. Liu, and S.-Y. Wang, 2001: Summer upper-level vortex over the North Pacific. Bull. Amer. Meteor. Soc., 82, 19912006, doi:10.1175/1520-0477(2001)082<1991:SULVOT>2.3.CO;2.

_ S.-Y. Wang, W.-R. Huang, and M.-C. Yen, 2004: Variation of the East Asian summer monsoon rainfall. J. Climate, 17, 744-762, doi:10.1175/1520-0442(2004)017<0744:VOTEAS>2.0.CO;2.
,-- , and M.-C. Yen, 2007: Enhancement of afternoon thunderstorm activity by urbanization in a valley: Taipei. J. Appl. Meteor. Climatol., 46, 1324-1340, doi:10.1175/JAM2526.1.

—, M.-C. Yen, J.-D. Tsay, C.-C. Liao, and E. S. Takle, 2014: Impact of the afternoon thunderstorm on the land-sea breeze in the Taipei basin during summer: An experiment. J. Appl. Meteor. Climatol., 53, 1714-1737, doi:10.1175/JAMC-D-13-098.1.

_ J.-D. Tsay, and E. S. Takle, 2015: The 850-hPa streamline charts for TS and no-TS days in Taipei Basin during 15 June-31 August over the period 2007-2013. Accessed 25 February 2016. [Available online at http://eamex.iastate. edu/publication/Synoptic_TS_NoTS.pdf.]

Cheng, M.-D., and K.-C. Lu, 2013: Fine information of Formosa weather (township weather forecasting) (in Chinese with English abstract). Project 100-1502-02-04-05, Central Weather Bureau, 6 pp. [Available online at http://astdr.colife.org.tw/ file_download.aspx?auto_id $=235 \&$ pid $=93$.]

Clark, J. D., 1983: The GOES user's guide. NASA Tech. Rep. C 55.202:983, 165 pp.

Faller, K., 2005: MTSAT-1R: A multifunctional satellite for Japan and the Asia-Pacific region. Proc. 56th Int. Astronautical Congress, Fukuoda, Japan, IACIAC-05-B3.2.04.

Hess, S. L., 1979: Introduction to Theoretical Meteorology. Krieger Publishing, $362 \mathrm{pp}$.

Huffman, G. J., and D. T. Bolvin, 2012: TRMM and other data precipitation data set documentation. NASA/GSFC, $37 \mathrm{pp}$. [Available online at ftp://precip.gsfc.nasa.gov/pub/trmmdocs/ 3B42_3B43_doc.pdf.]

Lawrence, M. G., 2005: The relationship between relative humidity and the dewpoint temperature in moist air. Bull. Amer. Meteor. Soc., 86, 225-233, doi:10.1175/BAMS-86-2-225.

Lefever, D. W., 1926: Measuring geographic concentration by means of the standard deviational ellipse. Amer. J. Sociol., 32, 88-94, doi:10.1086/214027.

Lin, P.-F., P.-L. Chang, B. J.-D. Jou, J. W. Wilson, and R. D. Roberts, 2011: Warm season afternoon thunderstorm characteristics under weak synoptic-scale forcing over Taiwan Island. Wea. Forecasting, 26, 44-60, doi:10.1175/2010WAF2222386.1.

,,,--- - $\longrightarrow$, and,- 2012 : Objective prediction of warm season afternoon thunderstorms in northern Taiwan using a fuzzy logic approach. Wea. Forecasting, 27, 1178-1197, doi:10.1175/WAF-D-11-00105.1.

Lindzen, R. S., 1968: The application of classical atmospheric tidal theory. Proc. Roy. Soc. London, 303A, 299-316, doi:10.1098/ rspa.1968.0052.

— 10, 3-188.

Liou, K. N., 2002: An Introduction to Atmospheric Radiation. 2nd ed. Academic Press, 583 pp.

Manzato, A., 2005: The use of sounding-derived indices for a neural network short-term thunderstorm forecast. Wea Forecasting, 20, 896-917, doi:10.1175/WAF898.1.

Schmeits, M. J., K. J. Kok, D. H. P. Vogelezang, and R. M. van Westrhenen, 2008: Probabilistic forecasts of (severe) thunderstorms for the purpose of issuing a weather alarm in the Netherlands. Wea. Forecasting, 23, 1253-1267, doi:10.1175/ 2008WAF2007102.1.

Yeh, T.-C., C.-T. Terng, L.-M. Huang, C.-T. Fong, and T.-H. Chang, 2012: The numerical weather prediction system of the Central Weather Bureau (I): Overview of the development of the system (in Chinese with English abstract). Meteor. Bull., 48 (4), 53-68. [Available online at http://photino.cwb.gov.tw/ rdcweb/lib/cd/cd07mb/4804_web/MB_48-4_forWeb-4.pdf.] 